Article

\title{
Circular Economy Development in the Construction Sector in Japan
}

\author{
Roope Husgafvel ${ }^{1, *(-)}$ and Daishi Sakaguchi ${ }^{2}$ (D) \\ 1 Department of Bioproducts and Biosystems, Aalto University, FI-00076 Espoo, Finland \\ 2 Department of Human Care Engineering, Faculty of Health Science, Nihon Fukushi University, \\ Handa 4750012, Japan; daishi@n-fukushi.ac.jp \\ * Correspondence: roope.husgafvel@aalto.fi
}

Citation: Husgafvel, R.; Sakaguchi, D. Circular Economy Development in the Construction Sector in Japan. World 2022, 3, 1-26. https:// doi.org/10.3390/world3010001

Academic Editor: Manfred Max Bergman

Received: 12 November 2021 Accepted: 17 December 2021 Published: 21 December 2021

Publisher's Note: MDPI stays neutral with regard to jurisdictional claims in published maps and institutional affiliations.

Copyright: (C) 2021 by the authors. Licensee MDPI, Basel, Switzerland. This article is an open access article distributed under the terms and conditions of the Creative Commons Attribution (CC BY) license (https:// creativecommons.org/licenses/by/ $4.0 /)$.

\begin{abstract}
The circular economy (CE) is about a system-level change towards sustainability, and it aims at keeping products, components, and materials at their highest utility and value at all times, covering both technical and biological cycles. This study aimed at exploring, discovering, describing, and synthesizing the characteristics of CE development in the construction sector in Japan based on the perspectives of sectoral organizations and focusing on the following themes: (1) sustainable production; (2) sustainable consumption; (3) creation and maintenance of value in a CE; (4) $\mathrm{CE}$ innovations; (5) CE of material and energy use; (6) technological, economic, and social barriers to CE; (7) CE guidance; and (8) specific CE aspects in the construction sector. This study applied a qualitative research approach, including a questionnaire survey as the specific method. This study addressed a gap in the research and helps to improve understanding of the CE development priorities based on the perspectives of organizations operating in or related to the construction sector in Japan. The findings indicate that the priority CE development focus areas in the construction sector in Japan encompass, for example, the use of sustainable and renewable raw materials; consumer awareness; and the design, use, and manufacturing of sustainable, recyclable, reusable, and repairable products, components, and materials. The barriers to CE that need to be overcome encompass, for example, the lack of general knowledge about circular economy opportunities and of seeing the "big picture" as well as issues related to economic benefits and the development of CE and sustainability-oriented products, components, and materials. Particularly important CE aspects in the construction sector include the maintenance of existing buildings; sustainability and the long-life cycles of products, components, and materials; CE-oriented product design; and sustainability criteria and cooperation between parties covering the whole life cycle of construction.
\end{abstract}

Keywords: circular economy; construction sector; Japan

\section{Introduction \\ 1.1. Circular Economy Development in the Construction Sector in Japan}

The circular economy (CE) is designed to be restorative and regenerative and it aims at keeping products, components, and materials at their highest utility and value at all times (technical and biological cycles) including (1) a focus on rethinking value creation and materials and energy use (e.g., due to growing resource pressures and supply chain and price risks); and (2) drivers such as alternative business models, economic losses, structural waste, regulatory trends, technological advances, and degradation of natural systems (due to a linear model) [1]. The overall aim of this study was to explore the characteristics of CE development in the construction sector in Japan based on the perspectives of sectoral organizations on the following themes: (1) sustainable production; (2) sustainable consumption; (3) creation and maintenance of value in a CE; (4) CE innovations; (5) CE of material and energy use; (6) technological, economic, and social barriers to CE; (7) CE guidance; and (8) specific CE aspects in the construction sector. Globally, there are many drivers for $\mathrm{CE}$ development in the construction sector, encompassing environmental concerns, 
climate change, resource and energy use, emissions, waste, and various sustainability concerns [2-9]. There is also a limited number of studies on CE and material efficiency in the Asia region, despite the boom in building construction [10].

The second World Circular Economy Forum (WCEF2018), which took place in Yokohama (Japan), concluded that CE plays a significant role in addressing the global sustainability crisis, including a reduction in global warming and emissions. Transition to the CE requires a shared vision of the $\mathrm{CE}$ that is connected to the Sustainable Development Goals (SDGs) [11], considering that there is an urgent need for both CE leadership and education for CE [12]. The Circular Economy Vision 2020 of Japan highlights the 3Rs (reduce, reuse, and recycle) which encompass the promotion of, for example, new business models (based on circularity as a management and business strategy), digital technologies, the establishment of a resilient resource circulation system, and consideration of new drivers (such as environmental considerations from society and markets) [13]. In Japan, the Sound Material Policy, which included a strong focus on the circulation of resources, has been a key instrument for the advancement of CE [12].

Advancement of CE requires collaboration between public and private sectors, including the role of the public sectors as the creator of a good operating environment to promote $\mathrm{CE}$ and the need to establish an institutional system that allows appropriate evaluation of companies and rewarding of their investments based on disclosed circular activities [11]. Japanese governmental approaches to promote $\mathrm{CE}$ and circularity have encompassed (1) education for awareness raising; (2) the development of circular trading markets for companies; (3) incentives; (4) public collaboration; (5) the customer-friendly collection of old appliances; (6) recycling laboratories and waste recycling; (7) the design for repair, reuse, and recycling; (8) long-lasting products and the use of recycled materials; (9) renewable sources; (10) recycling fees; (11) sorting and segregation; and (12) legislation and regulations (e.g., related to living and consumption) [14].

$\mathrm{CE}$ has not yet penetrated Japanese companies to a great extent in general. Even if the companies know the concept of $\mathrm{CE}$, they often view it as an extension of conventional environmental measures and as one of the regulatory responses. As well as in the construction sector, $\mathrm{CE}$ has also not been positioned in an effective manner in management strategies, and there is a lack of close coordination on the issue between management and business units in Japan [15]. CE development aims to achieve sustainable development and the CE concept is developed in four stages (including in Japan): (1) design; (2) production; (3) consumption; and (4) waste management [14]. For example, business model development and digital technology are essential for increasing the effectiveness of the $\mathrm{CE}$. The development of $\mathrm{B}$ to $\mathrm{C}$ and $\mathrm{B}$ to $\mathrm{B}$ business models and the effective use of digital technology will be key to increasing the effectiveness of the CE [15]. CE is oriented towards market solutions; therefore, firms and consumers are important actors which offer benefits for reducing transaction policy costs [16].

At present, there is no specific law to promote a circular economy in Japan. The closest law is the Act on the Promotion of Effective Utilization of Resources, which aims to break away from an economic society of mass production, mass consumption, and mass disposal, and achieve sustainable growth within the constraints of the environment and resources [15]. It has been noted that premature obsolescence could be addressed through a scalable demolition tax and that the government could introduce renovation or relocation incentives, inform stakeholders about the need to improve the quality of living to address living in delayed obsolete buildings, and address the issue of empty houses [17]. The Construction Recycling Material Act has been enacted in Japan and covers demolition work related to buildings using concrete, asphalt concrete, or wood as specified construction materials, or new construction work that uses specified construction materials. Specifically, for construction work above a certain scale (subject construction work), the contractor is obligated to carry out sorted dismantling and recycling [15].

In the past, recycling generated wastes (reuse as raw materials) was the core of the measures; however, in order to comprehensively promote reduce, reuse, and recycle, 
measures are now being taken under seven schemes, including specified resource-saving industries and designated reuse-promoting products [15]. CE-related development in Japan has mainly focused on the recycling and reduction in waste generation (e.g., use of policy and legal instruments) [18]. It has been noted that recycling has been successfully increased in Japan, including a significant reduction in landfilled waste [19]. There are approaches related to the measurement of $\mathrm{CE}$ in Japan that have contributed to very high recycling rates, including an indicator for the cyclical use rate of materials, resource productivity indicator, and an output indicator for landfilled waste. Furthermore, these are also supplemented by sector-specific measurements. Indicators of societal effort towards $\mathrm{CE}$ have also been applied in Japan, including the size of the market for rental and leasing of goods, the amount of sold reusable packaging, and the number of local authorities that charge for residual waste collection [20].

Important future $\mathrm{CE}$ development focus areas include e.g., the increase in public awareness creation (e.g., consumers) and involvement of both the civil society and the business community [18]. Enabling regulations and policies, collaboration, and support from all stakeholders (e.g., consumers) are important for the successful implementation of CE [14]. In general, the Japanese system for the design of a CE is based on comprehensiveness, collaboration, and incentivizing all actors to do the right thing (e.g., public spirit) which encompass several elements. These include (1) co-ownerships of recycling infrastructure (e.g., whereby companies invest in recycling infrastructure and disassembly processes, and manufacturers operate disassembly plants to recover materials and parts); (2) consumer-friendly collection; and (3) upfront consumer fees [20]. There is a need to develop new policies to advance CE in Japan, including specific policy concepts and institutional infrastructure, which cover, e.g., the promotion of the concepts to reduce and reuse, end-of-product attitudes, and the handling of potentially polluting parts and materials [19].

It has been noted that all residential buildings should serve the society in Japan, and there is a need to design different strategies in the built circular environment for different population segments and to apply specific measures to counteract the psychological causes of the current situation including focus on markets, governance, taxing, and local and national governmental programs that address specific social norms and encourage longer use, improvement, and maintenance of houses [17]. In addition to the construction of systems to expand the value of $\mathrm{CE}$, it is also necessary to develop human resources involved in $\mathrm{CE}$. Thus, there is an urgent need for industry-academia-government cooperation to develop human resources with sensitivity who can incorporate coexistence with nature into their daily lives and business [21]. For example, Japanese buildings are short-lived due to non-technical reasons, and a people-centered approach is the most effective method to address premature obsolescence, including a case-by-case focus and objective assessment/judgement of the time of justified obsolescence which consider multiple stakeholders, benefits, costs, and the cradle-to-grave environmental assessment of benefits associated with the construction of a new building and of the lifespan extension of the existing building [17].

\subsection{Pre-Study Survey}

Prior to the initiation of this study, a questionnaire survey was implemented in the World Circular Economy Forum Side Event (Construction and Circular Economy) in Helsinki on 5 June 2019, and its results provided some orientation and background information for this study. This qualitative research approach [22] applied a questionnaire survey [23-26] as a method including focus on CE drivers, opportunities, barriers, and steering approaches in the construction sector. This seminar type event provided an opportunity to implement a brief as well as an overall and initial scoping of the topic. The objective was to collect general information to describe knowledge and preferences of respondents [27] that had interest on and experience of $\mathrm{CE}$, specifically in the context of the construction sector. This approach was chosen due to its short implementation time, easy analysis, and potential to provide a lot of information from a lot of people [24], considering 
that closed questions are easy to compare and process as well as suitable for testing specific focus areas [28].

The survey focused on both opportunities and problems [29] and were designed professionally [30] based on responses that were specified by researchers [31], including clear questions that were easy to answer [30]. The structure of questionnaire was formal and structured with multiple choice closed questions, including the provision of an open "Other" answering option for both CE drivers and opportunities and barriers to CE in the construction sector. The answering options for two questions were: "please select 1-5 options" and for one question there was a selection between "very important", "important", "partly important", or "not at all important". The specific survey questions and answering choices/options were based on (1) a literature review and previous studies; (2) the key aspects of circular economy development with particular emphasis on the construction sector; and (3) own previous research, including face validity (peer review) [29], to check the quality of the questionnaire in terms of the purpose of this event and the needed information.

The survey was anonymous and voluntary for the participants of that event. Its respondents encompassed 27 people from many sectors related to construction (Figure 1), including participants from other sectors, such as infrastructure- and sustainability-related organizations. The results are presented as figures based on the chosen key themes and associated answers to the survey questions with the idea to both identify and indicate the most preferred options in each theme. The results indicated that the most important CE drivers and opportunities in the construction sector (Figure 2) are (1) products that are designed to be repairable and reusable; and (2) sustainability and long-life cycles of products, components, and materials. Other important areas included (1) the maintenance of existing buildings (renovation and restoration); (2) components and materials that are designed to be dismantled and reused; (3) digital solutions for building/material recycling (buildings as material banks); and (4) the utilization of construction and demolition wastes as raw materials.

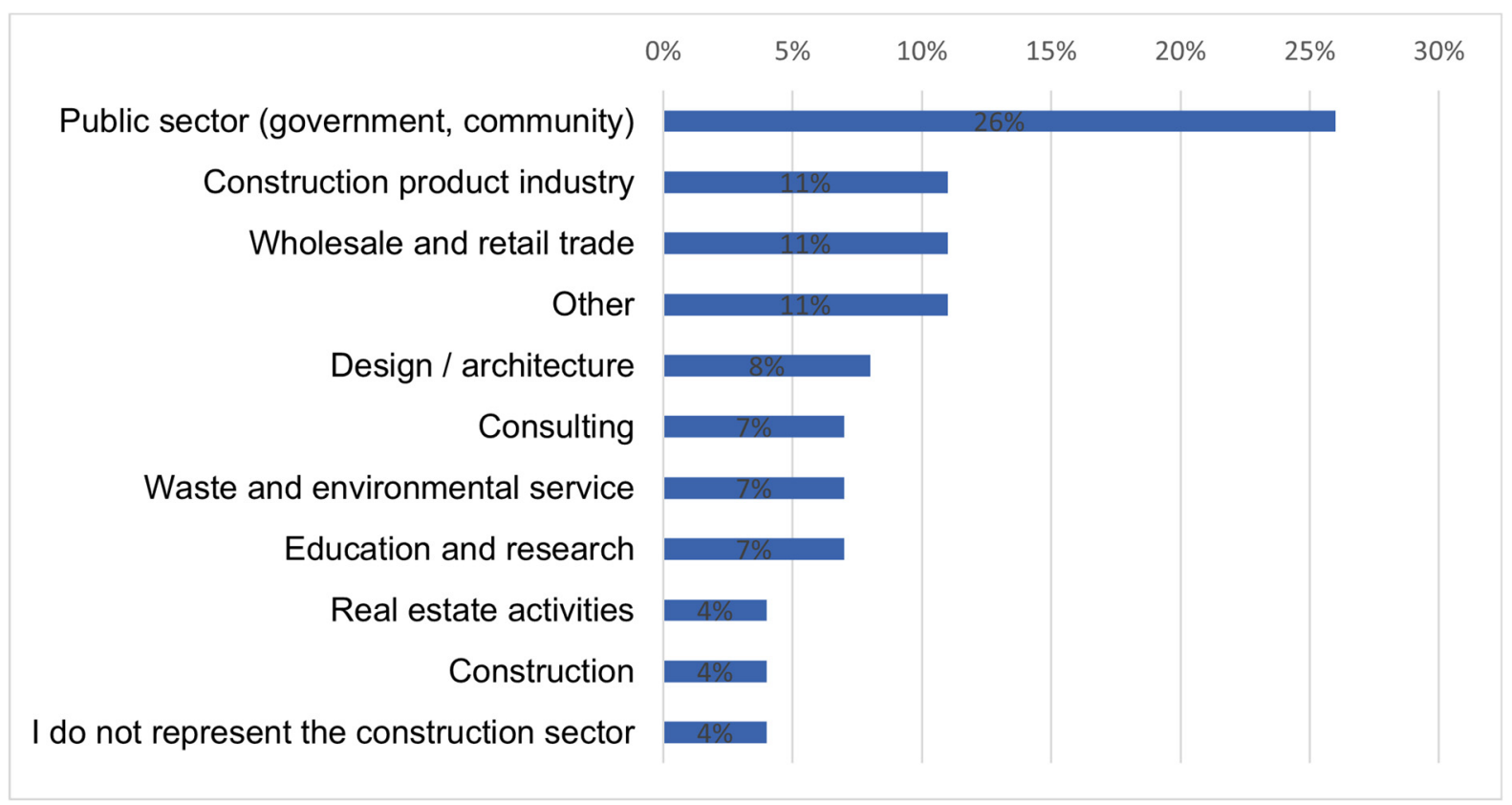

Figure 1. Represented sectors of respondents. 
Products that are designed to be repairable and reusable

Sustainability and long life cycles of products, components and materials

Maintenance of existing buildings (renovation and restoration)

Components and materials that are designed to be dismantled and reused

Digital solutions for building/material recycling (Buildings as Material Banks)

Utilization of construction and demolition wastes as raw materials

Design of completely new products, components and materials

Use of recycled material

Development of recycling and sorting methods

Use of renewable raw materials

Supplementary construction (increased construction and new uses for buildings)

Material exchanges/demolition auctions (channel for recycled materials)

Repair and maintenance without dismantling of structures

Renting and product and component leasing

Development of recycling logistics

Other

Changing of demolition practices

Utilization of construction and demolition wastes as energy (plastics and wood)

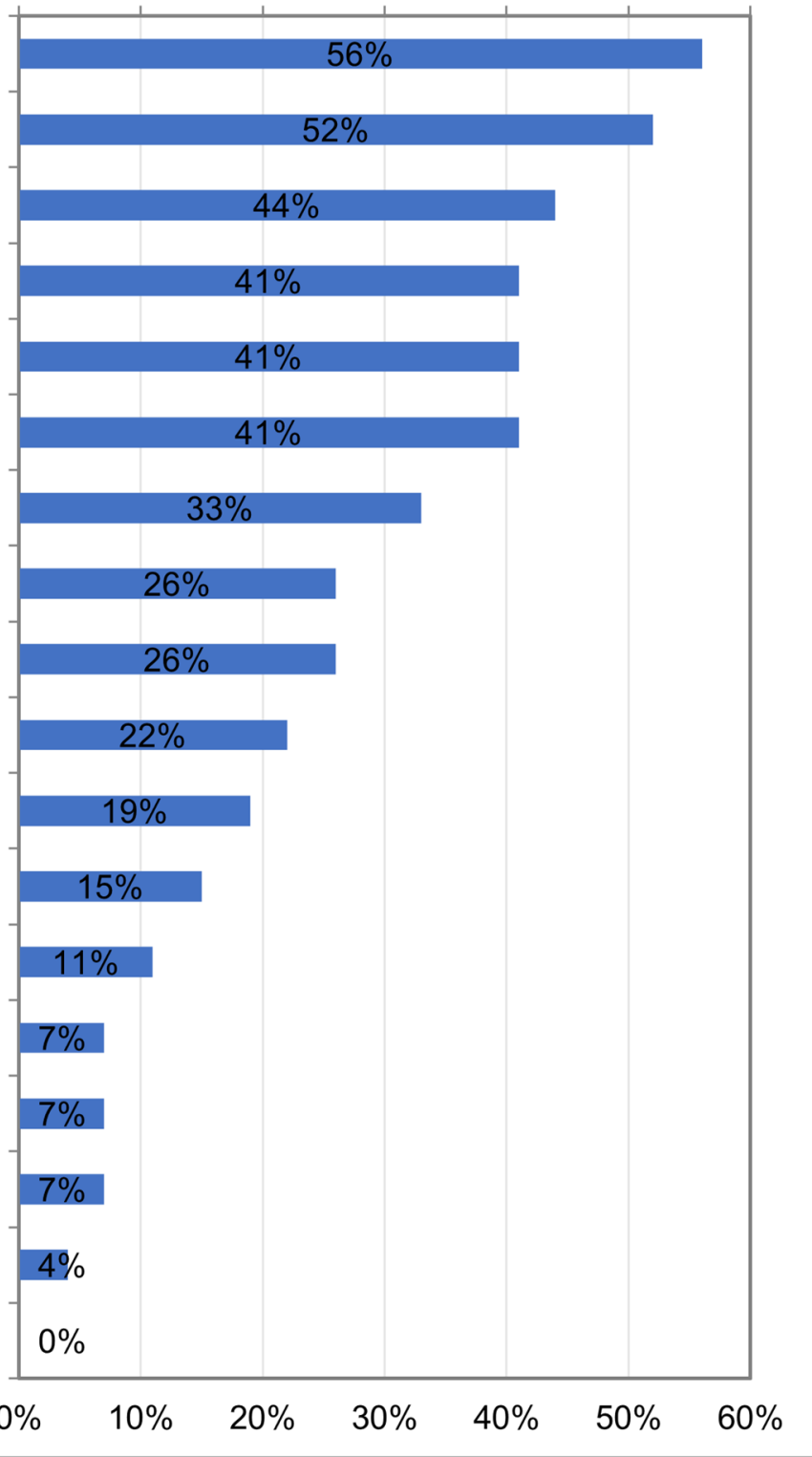

Figure 2. Most important circular economy drivers and opportunities in the construction sector.

The most important barriers to CE in the construction sector (Figure 3) included (1) low economic benefit associated with sorting and recycling (profitability) and (2) insufficient monitoring data about construction wastes (for example quantity and quality). Other important barriers included (1) the design and implementation practices that prevent material-saving demolition and (2) the lack of general understanding of CE opportunities. An open "Other" answering option was also provided for both CE drivers and opportunities in the construction sector (Figure 2) and barriers to $\mathrm{CE}$ in the construction sector (Figure 3). 


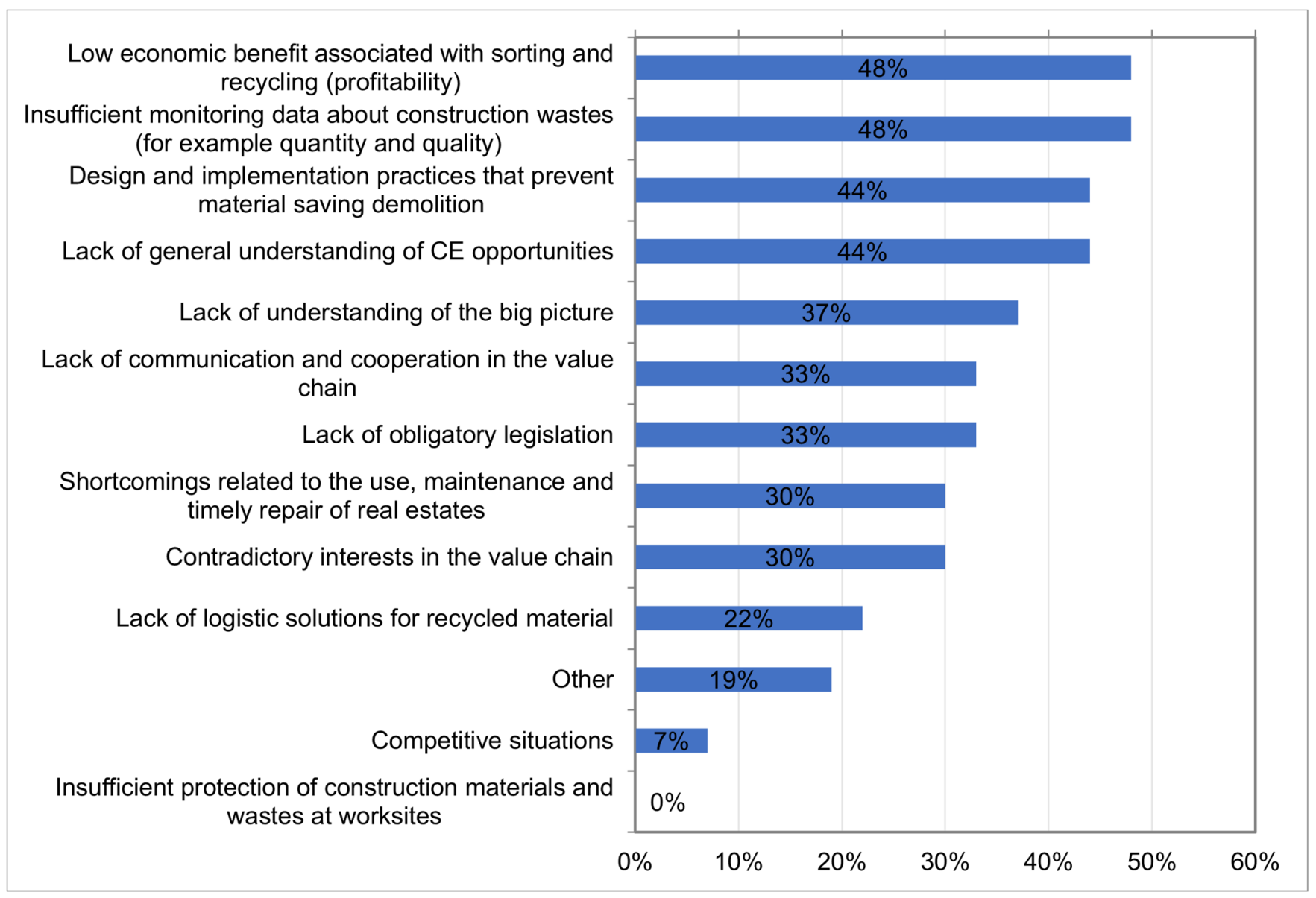

Figure 3. Most important barriers to circular economy in the construction sector.

The answers to the former included consideration of existing buildings as valuable (demolition not as a baseline) as well as planning and development of the operating models of areas and the society, whereas the answers for the latter encompassed legislation, permitting, know-how, a visionary approach, and difficulties related to recycling and reuse of the products in existing buildings. The most important steering approaches for CE in the construction sector (Figure 4) included (1) cooperation between the parties of the construction life cycle; (2) sustainability criteria for the whole life cycle (environmental, economic, and social); (3) the loosening of waste and chemical legislation to promote product recycling and reuse; and (4) CE criteria for all project stages. 
Cooperation between the parties of the construction life cycle

Sustainability criteria for the whole life cycle (environmental, economic and social) Loosening of waste and chemical legislation to
promote product recycling and reuse

CE criteria for all project stages

Guide for the planning and implementation of demolition work

Demolition audits (investigation of recycled materials)

Minimum requirement for the use of recycled material in construction (for example $20 \%$ of materials must be recycled)

Mandatory recyclability of products, components and materials

Minimum requirement for the recycling of construction and demolition wastes (for example $50 \%$ in all construction sites)

Voluntary targets for the recycling of construction and demolition wastes (EU $70 \%$ recycling target)

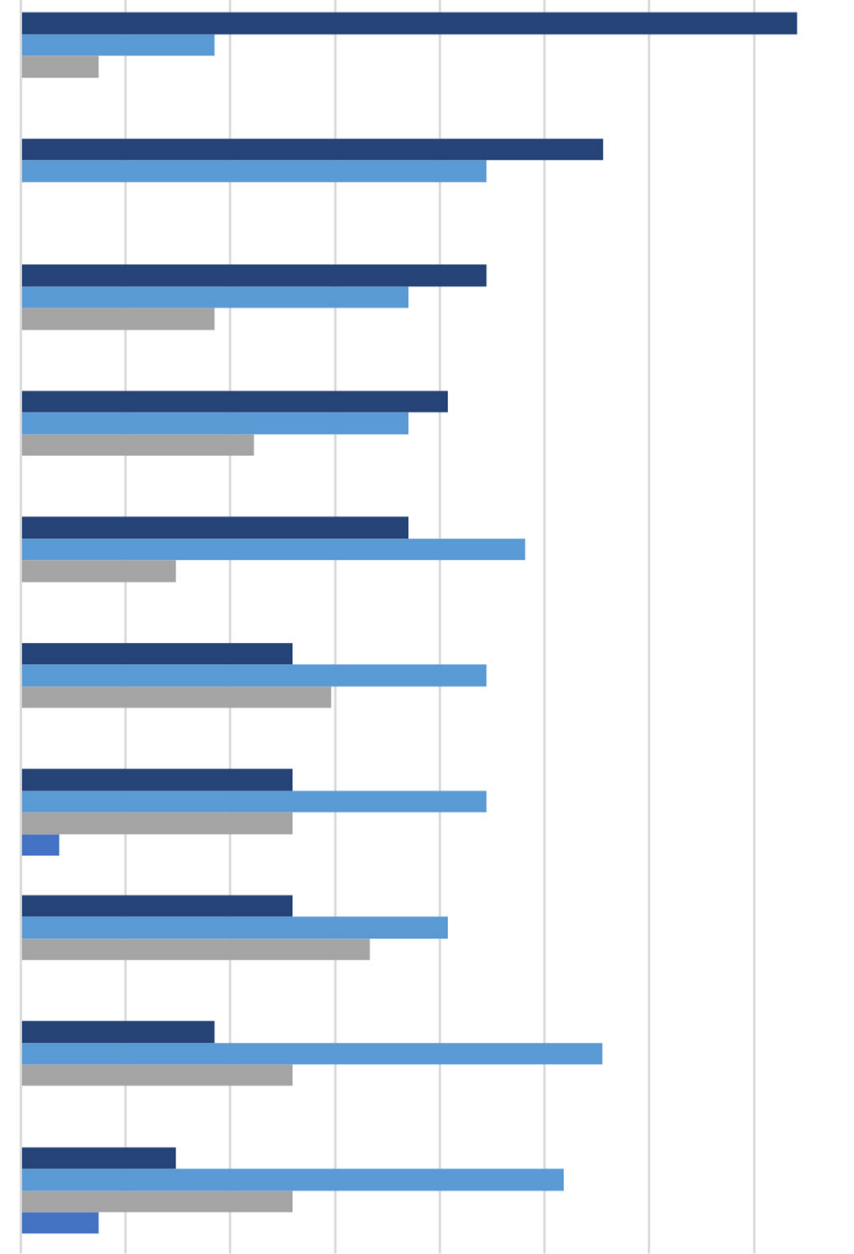

0,00\% 10,00\% 20,00\% 30,00\% 40,00\% 50,00\% 60,00\% 70,00\% 80,00\%

- Very important $\quad$ Important $\quad$ Partly important $\quad$ Not at all important

Figure 4. Importance of specific steering approaches for circular economy in the construction sector.

\section{Materials and Methods}

This study aimed at exploring, discovering, describing, and synthesizing the characteristics of CE development in the construction sector in Japan based on the perspectives of sectoral organizations and the following themes: (1) sustainable production; (2) sustainable consumption; (3) the creation and maintenance of value in a CE; (4) CE innovations; (5) CE of material and energy use; (6) technological, economic, and social barriers to CE; (7) CE guidance; and (8) specific CE aspects in the construction sector. This study is important because it addresses a gap in the research and contributes to an improved understanding of the CE development priorities based on the perspectives and organizations operating in or related to the construction sector in Japan.

This study applied a qualitative research approach based on the idea that the research approach needs to be defined based on the purpose of the study [22]. The chosen method was a questionnaire survey [23-26]. An online survey was applied as an information collection method to describe, explain, and compare knowledge, preferences, attitudes, values, and behaviors of respondents [27], as well as to gain benefits associated with questionnaires (such as short implementation time, easy analysis, and a lot of information from a lot of people) [24]. In addition, closed questions (1) are easy to compare and process; (2) do not require much time; and (3) are good for testing specific focus areas [28]. The 
construction of effective questions often requires both creativity and expertise, supported by the review of both opportunities and problems [29]. Closed-end questions also include all possible responses, as specified by the researchers [31], and the questionnaire should be professionally designed and look easy to answer with clear questions [30].

The questionnaire was formal and structured with multiple choice closed questions. However, some questions allowed optional own answers under the "Other" choice. In the beginning, there were two questions pertaining to the sector of business and the number of employees. In the chosen approach, the survey questions focused on the following themes: (1) sustainable production; (2) sustainable consumption; (3) the creation and maintenance of value in a CE; (4) CE innovations; (5) CE of material and energy use; (6) the technological, economic, and social barriers to $\mathrm{CE}$; (7) CE guidance; and (8) specific CE aspects in the construction sector. This study focused on overall themes that can be applied in many contexts/levels, and our further research will address more detailed areas and themes, including more in-depth focus on cultural/traditional, sustainability, design, and engineering aspects.

The specific survey questions and answering choices/options were based on (1) literature review and previous studies; (2) the key aspects of circular economy development, with particular emphasis on the construction sector; (3) previous research and online sources on CE in Japan, including focus on the construction sector and buildings; (4) sustainability considerations; (5) own previous research; and (6) the earlier orientation and background pre-study survey that was implemented in the World Circular Economy Forum Side Event (Construction and Circular Economy) in Helsinki on 5 June 2019. Face validity (peer review) [29] was also applied to check the quality of the questionnaire and of specific questions and themes, considering that the construction of effective questionnaires requires both creativity and expertise supported by the review of both opportunities and problems.

The questionnaire was sent to 324 respondents, and the response rate was 35\% (113 organizations). The sectors and profiles of the respondents are presented in Figures 5 and 6. The questionnaire was only sent to full-time experts of each organization (via email) and the respondents were asked to answer each question from the point of view of their organization. The administrative staff, technical staff, and temporary workers were not included. The answering options for the closed question of the survey were: "please select 1-5 options", except for one question that included selection between "very important", "important", "partly important", or "not at all important". The results are presented as figures based on the chosen key themes and associated answers to the survey questions with the idea to both identify and indicate the most preferred options in each theme.

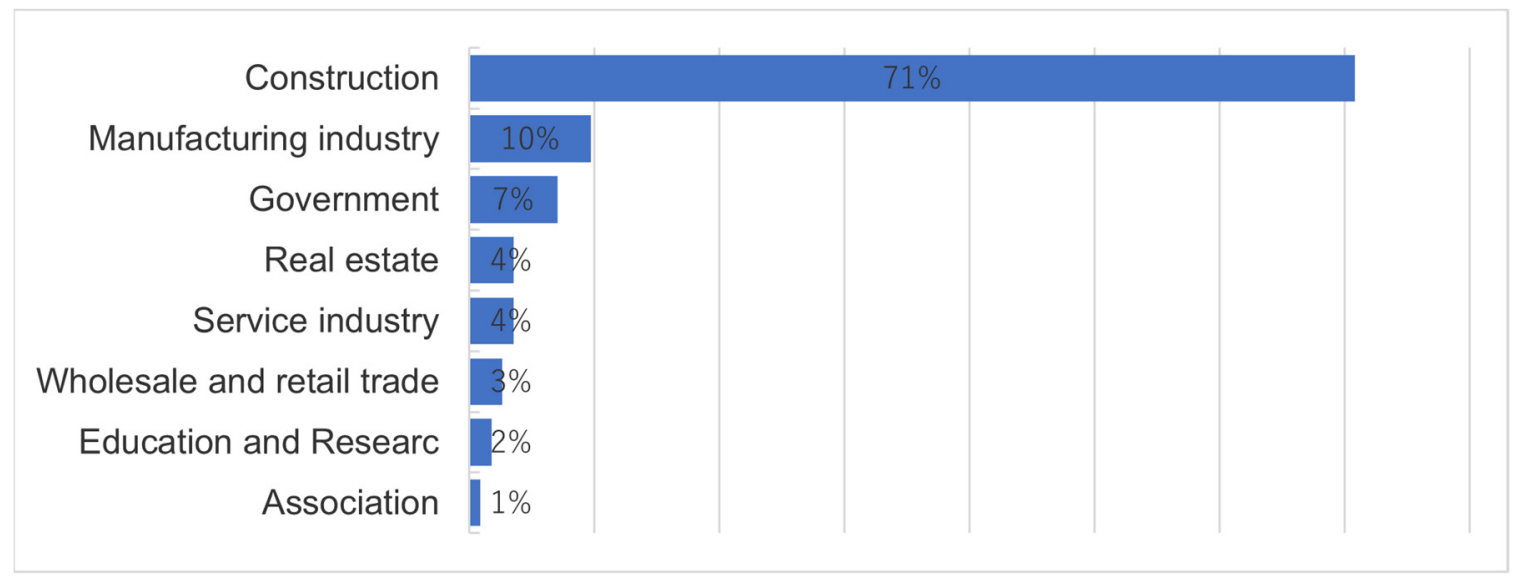

Figure 5. Business sectors. 


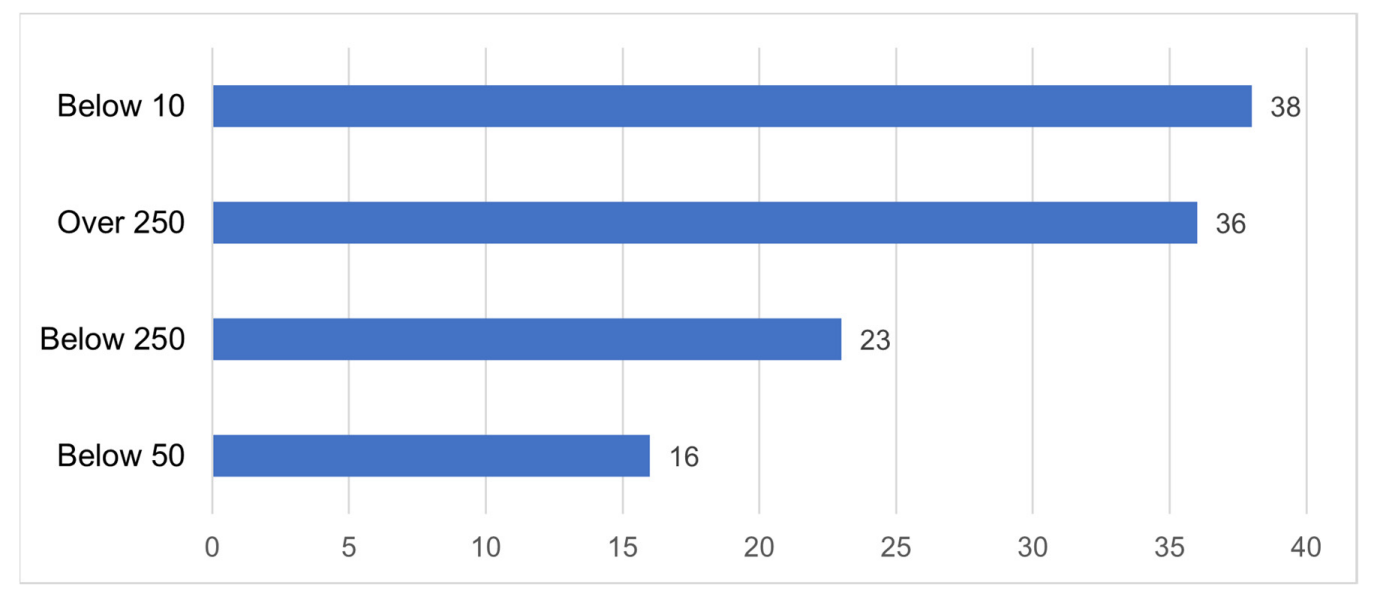

Figure 6. The number of employees.

\section{Results and Discussion}

\subsection{Sustainable Production}

The results indicate that the best approach to promote sustainable production is the use of renewable raw materials (Figure 7). Other preferred options encompassed (1) recycling; waste minimization and utilization of wastes as raw materials; (2) sustainable, recyclable, reusable, and repairable products, components, and materials; and (3) the enhancement of economic and social benefits. In addition, the answers for the other approaches to promote sustainable production encompassed (1) the promotion of ESG investment to evaluate sustainability (which tend to be focused on large companies) and the support system for sustainable manufacturing facilities for SMEs; (2) the establishment of a cycle of reproduction (sustainable resource) of wood (currently scarce); and (3) contact with countries (such as China) that have a large negative impact on the environment.

It is highly noteworthy that renewable raw materials are highlighted in this context, which implies that strong focus is needed on, for example, the sustainable use of wood in construction and buildings, considering the sustainability and circularity of associated products, components, and materials (including sustainable forest management). Interestingly, sustainable and renewable raw materials were also identified to be one of the most potential areas to create significant CE innovations, as a particularly important area in the development of CE guidance. These findings support some previous ideas [11,12] about CE development in Japan, including the importance of sustainability, as outlined by the SDGs, including, e.g., the sustainable use of all natural resources. They also support the findings of previous studies about the importance of renewable sources [14]; sustainability strategies for the realization of a circular built environment in Japan (e.g., to address societal and environmental concerns related to short-lived buildings, including social circular strategies for the residential built environment) [17]; and sustainable development for CE development in Japan [14]. It has been noted that sustainable construction is important due to the limited number of natural resources and new construction methods, such as modular construction as a growingly important off-site construction method, which can contribute to enhanced sustainability [32]. 


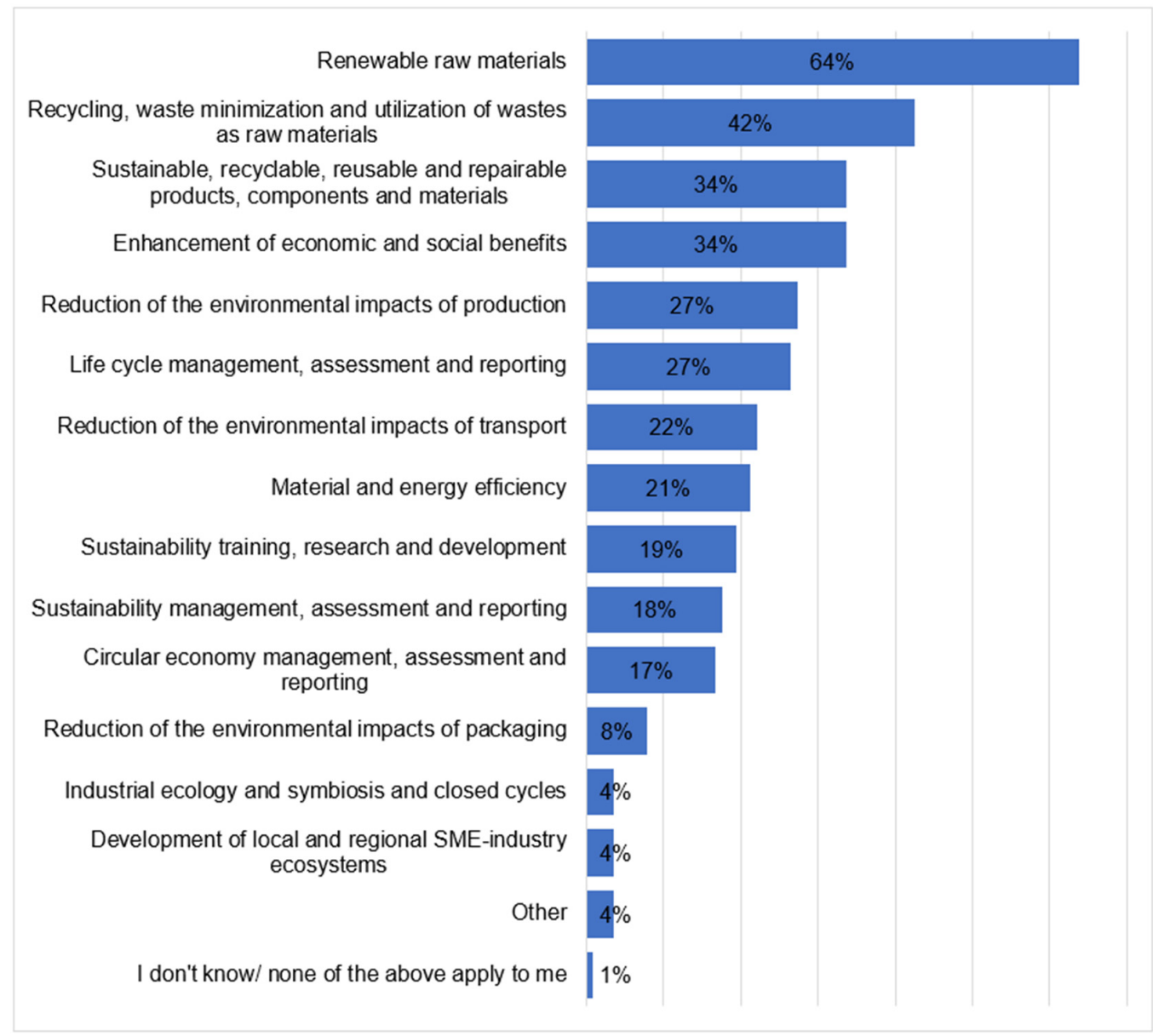

Figure 7. The best approaches to promote sustainable production.

The concept of sustainable building is related to both environmental characteristics and social, cultural, and economic indicators [33]. The CE model promotes a transition to more sustainable production models, and it can promote significant sustainability improvements in the construction industry [34]. Sustainable building and associated approaches demonstrate a move towards achieving sustainable development in the building industry, considering environmental, social, and economic issues [35]. CE is a topical concern in the construction industry, and it has been acknowledged as a way forward for sustainable development [8]. In addition, CE contributes to a more sustainable economy, and CE concepts are well-suited to the building and construction sector in cities [36]. The design of frameworks, indicators, methods, and tools to measure the circularity of products could consider the connection to social, environmental, and economic pillars of sustainable development, adaptation to specific industry contexts and product characteristics, and system and life cycle thinking [37]. The promotion of CE and sustainability in the built environment requires that the circular economy potential of construction and demolition waste should be addressed from a holistic perspective considering social (e.g., social justice and resilience of local communities), economic (e.g., new local jobs and business instead of landfilling), environmental (e.g., reduced greenhouse gas emissions), spatial, and temporal aspects [38].

Knowledge gaps that need to be addressed encompass product design, potential, and limitations related to long-lived products and avoidance of waste generation [39]. Societal drivers for $\mathrm{CE}$ in the construction sector include challenges related to resource scarcity and climate change, as well as the prolonging of construction material life cycles, which can create significant environmental benefits (e.g., the substitution of virgin raw materials and a reduction in carbon emissions) [40]. The promotion of sustainable building 
practices requires measures to balance environmental, social, and economic performance in the implementation of construction projects considering (1) links between sustainable development; (2) the need to change the ways that construction practitioners think about and apply information in the assessment of building projects and construction; and (3) the implementation of sustainability principles in the building industry [35].

A sustainable future requires system-based thinking including balanced consideration of society, the environment, and economics [41]. In addition, previous studies have recognized that (1) information-centric $C E$ implementation will lead to the achievement of sustainable development goals in the construction industry [8]; (2) resource recovery, resource-efficient building construction, or CE-related LCA studies on construction and buildings are not often addressed in studies [42]; (3) future research and work should focus on the effective reuse of construction materials and waste-free recycling to promote $\mathrm{CE}$, environmental preservation, and sustainable development [43]; and (4) CE can contribute to more sustainable business models provided that the social dimension (e.g., ethical), ecosystem functioning, and human well-being are all addressed in this context [41]. For example, sustainable construction is one of the best options to reduce the environmental impact of buildings. Furthermore, the integration of building information modeling (BIM) with life cycle assessment (LCA) can create significant benefits in the evaluation of whole life cycles of buildings, including focus on the selection of sustainable materials early in the design phase, for example [44].

\subsection{Sustainable Consumption}

The results indicate that the best approach to promote sustainable consumption is the enhancement of consumer awareness (Figure 8). Other preferred options include recycling, waste minimization, the utilization of wastes as raw materials, and willingness to pay higher prices for sustainable products and services. In addition, the answers to other approaches for promoting sustainable consumption include (1) social recognition that sustainability is not a "condition for making money" but a "minimum requirement" for business transactions, and that sustainability management is a mechanism for streamlining production and consumption processes and improving economic efficiency; (2) psychological brake on purchasing products made from virgin materials (e.g., a system similar to charging for plastic bags); (3) the promotion and financing of sustainable consumption through taxation, including a carbon tax; (4) public subsidies for development, leading to a beneficial impact on the environment, economy, and society; (5) relaxation of legal restrictions on construction; (6) pricing of sustainable products and services in a way that that they are not expensive; (7) development of systems and rules that encourage consumers to choose sustainable products and services; (8) motivational incentives; and (9) strengthening of product distribution among environmentally conscious countries (outside of China).

These findings highlight the importance of consumer awareness for sustainable consumption. This implies that the promotion of sustainable CE development requires that end-users, customers, and consumers (preferably the whole society) have sufficient awareness about the benefits of both $\mathrm{CE}$ and sustainability. The lack of consumer awareness was also identified as a major barrier to CE development, and the enhancement of consumer awareness was identified as a particularly important area in the development of CE guidance. In addition, recycling, waste minimization, and utilization of wastes as raw materials were found to be important for both sustainable production and consumption. These findings also support some earlier ideas [18] about the importance of public awareness creation (e.g., consumers) and the involvement of both the civil society and the business community for CE development in Japan. 


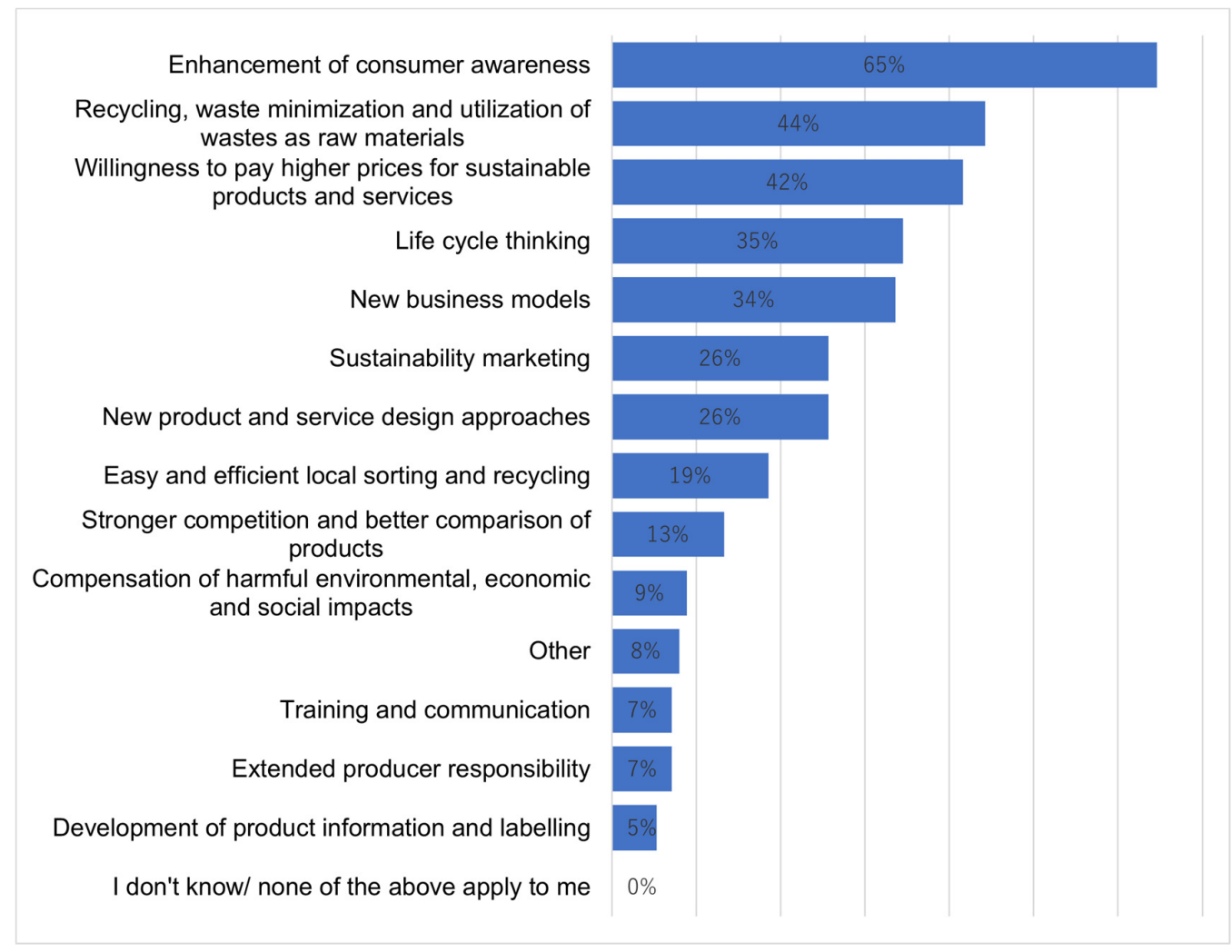

Figure 8. Best approaches to promote sustainable consumption.

The implementation of $\mathrm{CE}$ in the construction sector requires, for example, reorganization at the system level, changes across the whole of the value chain, and the development of new consumer habits [45]. CE requires a transformation of both production and consumption systems, and implementing CE practices transforms the way companies do business especially in the manufacturing industry [46]. The production of recycled products and the reuse and recycling of construction and demolition wastes provide environmental and economic benefits in most cases [47]. In general, CE can promote better resource management and efficiency, and can support also waste elimination (including specific strategies to implement $\mathrm{CE}$ in the building environment, such as early selection of appropriate building materials and components to enhance the integration of $\mathrm{CE}$ principles into the whole value chain and to create closed-loop systems) [48].

Previous studies have also acknowledged that (1) CE and the SDGs can also be promoted in novel contexts, such as emergency housing [49]; (2) social sustainability initiatives (e.g., engagement with residents and information about the use of buildings) are largely absent from the design of sustainable settlements, which has a negative influence on both the sustainability of large settlements and the environmental performance of buildings [50]; (3) it is important to consider that the environmental and economic sustainability of the CE framework is site-specific and depends on multiple factors, such as the type of material, building elements, transport distances, and economic and political context [47]; and (4) the next generation of sustainable buildings needs to adopt a broader perspective in terms of social and environmental sustainability, including organizational and physical layout of settlements [50]. In addition, the design for circular production processes and circular consumption, including a focus on system changes, can promote CE [51].

\subsection{Value Creation and Maintenance}

The results indicate that the best way to create and maintain value in a $\mathrm{CE}$ is the design and manufacturing of sustainable, recyclable, reusable, and repairable products, components, and materials (Figure 9). Other preferred options encompassed the develop- 
ment of markets for recycled products, components, and materials, as well as life cycle thinking. In addition, the answers for the other options to create and maintain value in a CE include (1) the diversification of funds into the resource recycling sector, as a system that can balance regulation and support; (2) education on circular economy; (3) cost reduction and economic penalties for non-cyclical economies; (4) improvement of understanding and developing of the entire product value chain; and (5) the provision of attractive and effective technologies that are necessary to achieve sustainability.

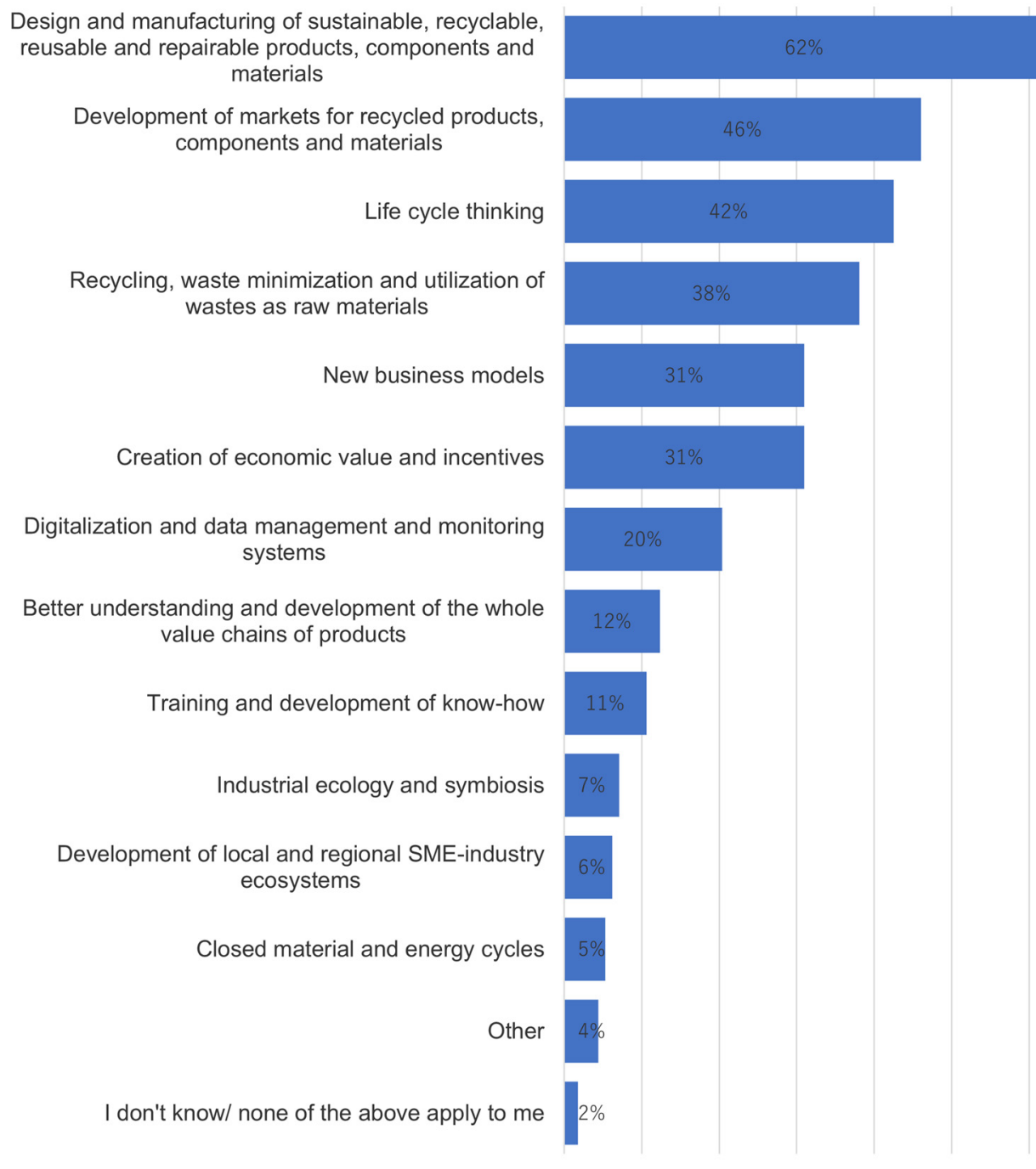

Figure 9. The best ways to create and maintain value in a circular economy.

These findings highlight the importance of sustainable and CE-oriented products, components, and materials, based on life cycle thinking and supported by market creation. The sustainable and cascading use of wood [39,40,52-57] can be used to promote value creation and maintenance in the construction sector. For example, cascading of wood from demolished buildings requires focus on primary design; the development of jointing systems; and consideration of the reuse of whole elements of the unit parts with special emphasis on the location, the demolition method, and recovered length and condition (instead of the cross-sectional dimension) that determine the potential cascading flow and applications [52]. It has been noted that CE of timber is not typically considered or put into practice in the construction sector, and that the promotion of $\mathrm{CE}$ for wood in construction requires e.g., a focus on the economic value of the waste material along the whole value chain [40]. These findings are also in accordance with previous findings 
about the importance of recycling $[19,20]$, the concept of reuse [19] and design for repair, reuse and recycling, long-lasting products, and the use of recycled materials [14] for CE development in Japan.

Additionally, CE adoption in BIM-based LCA of buildings is still limited and there is a lack of focus on (1) the assessment of whole buildings; (2) circularity (especially the reusability and recyclability of the materials); and (3) the refurbishment and demolition processes of buildings [44]. Preconstruction and demolition strategies have a significant influence on $\mathrm{CE}$ in the construction and demolition waste sectors because they provide waste minimization approaches and enhance the recovery and use of construction and demolition wastes as secondary materials [58]. In addition, the deconstruction of all types of buildings can be a sustainable and viable alternative to demolition; it requires focus on planning and design for disassembly and reuse, the selective dismantling of building components for future reuse, repurposing or recycling, a reduction in building complexity, smart choice of materials, access to construction and deconstruction information, and life cycle thinking [59]. Material recovery is an essential stage for CE in the construction and demolition waste sectors, but the development of secondary materials market is limited by consumer attitudes towards using recovered materials (due to the lack of quality standards) and low demand and high prices of secondary materials compared to primary raw materials [58].

\subsection{Innovations}

The results indicate that the most potential areas to create significant $\mathrm{CE}$ innovations are sustainable, recyclable, reusable, and repairable products, components, and materials, as well as sustainable and renewable raw materials (Figure 10). In addition, the answers for the other potential areas to create significant CE innovations include (1) an intellectual property platform for environmental technologies that is not bound by patents; (2) changing consumer attitudes; (3) the establishment of renewable energy; and (4) a focus on all of these aspects, including the contribution of small companies to many of them and consideration of the influence of the public consciousness (always influenced and spread in minute details) on the limited development of a circular economy society.

The findings highlight the importance of sustainable and CE-oriented products, components, and materials, as well as sustainable and renewable raw materials. Therefore, the sustainable and cascading use of wood [39,40,52-57] is also essential in this context. For example, it is possible to technically achieve the reuse of structural timber and there is a need for efficient and standardized assessment criteria to guarantee mechanical properties and to ensure the structural safety of buildings [40]. For the cascading use of wood, both the cross-section and location of the use should be considered, and the disassembly design could enhance the potential of cascading use [56]. These findings also support some previous ideas [13] and findings of a previous study [15] about the importance of new business models for CE development in Japan. They also support the importance of the 3Rs (reduce, reuse, and recycle) for CE development in Japan [13]. In addition, these findings are in accordance with previous findings about the importance of recycling $[19,20]$; the concept and design of repair, reuse, and recycling [19]; long-lasting products; and use of recycled materials [14] for CE development in Japan. 
Sustainable, recyclable, reusable and repairable products, components and materials

Sustainable and renewable raw materials

New business models

Material and energy efficiency

Development of markets for recycled products, components and materials

Recycling and utilization of wastes as raw materials

New product and service design approaches

Digitalization and data management and monitoring systems

Reduction of the environmental impacts of production

Easy and efficient local sorting and recycling

Reduction of the environmental impacts of transport

Development of local and regional SME-industry ecosystems

Reduction of the environmental impacts of packaging

Development of product information and labelling

Industrial ecology and symbiosis and closed cycles
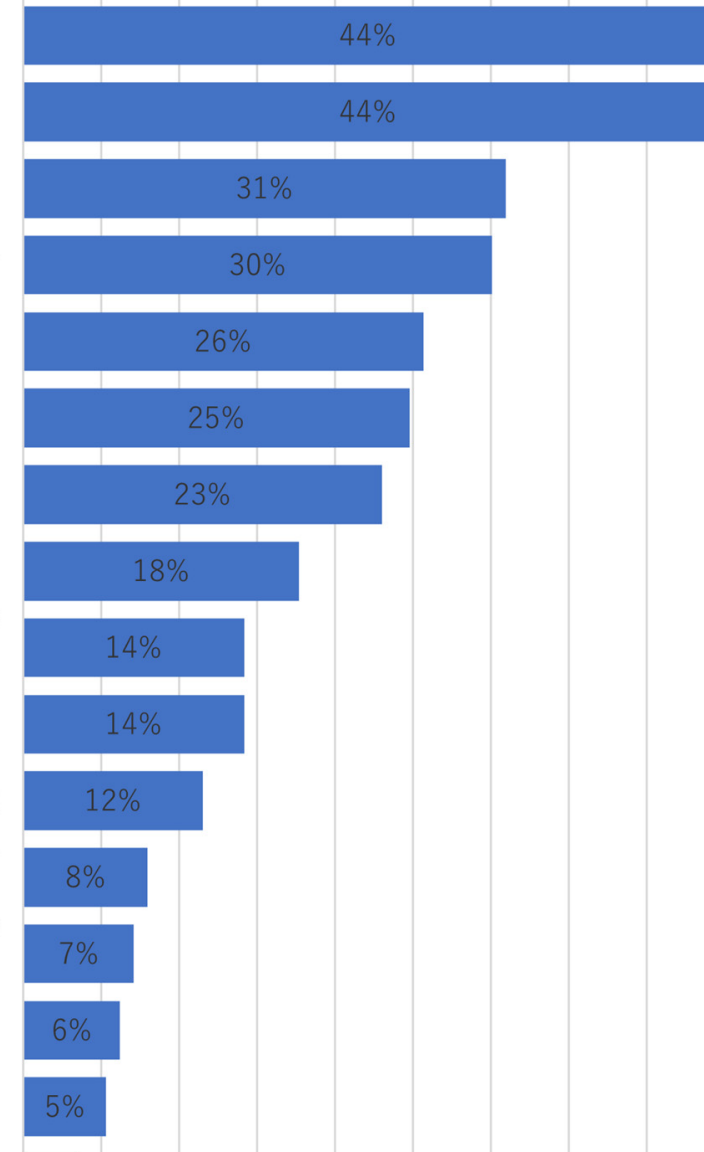

Other

I don't know/ none of the above apply to me

Figure 10. The most potential areas to create significant circular economy innovations.

The design of sustainable buildings is important, and the construction sector needs to be oriented towards sustainable development [33]. For example, the key competencies for design in a CE include: (1) circular systems thinking; (2) design for recovery; (3) design for multiple-use cycles; (4) circular business propositions; (5) circular user engagement; (6) circular materials and manufacturing; (7) circular impact assessment; (8) circular economy collaboration; and (9) circular economy storytelling [60,61]. In addition, design for a CE requires the development and implementation of a specific set of competencies, methods, and tools [61]. Furthermore, designers need to respond to new social, economic, and environmental needs; adopt a holistic approach to problem solving; and apply new design thinking and practices (e.g., integration of CE criteria) to lead CE development [6]. It is noteworthy that the early stages of design are decisive for the overall performance of buildings [62]; that circular design is about redesigning products, business models, cities, and linear systems covering, e.g., the extension of product life, designing out waste, and pollution, design for repair, remanufacturing and reuse, the use of circular and safe materials, modular design, and dematerialization (e.g., moving from products to services) [63]; and that the sustainable design, construction, and use of buildings can be based on the evaluation of environmental impacts and pressure, social aspects and benefits (e.g., user comfort), and economic aspects (such as life cycle costs) [33]. 


\subsection{Material and Energy Use}

The results indicate that the best approaches to promote CE of material and energy use are sustainable, recyclable, reusable, and repairable products, components, and materials, as well as material and energy efficiency (Figure 11). In addition, the answer for the other approaches to promote $\mathrm{CE}$ of material and energy use included the establishment of a low-cost recycling system (e.g., the collection of used paper and critical consideration related to the recycling of plastics, including in the context of the bottle collection system).

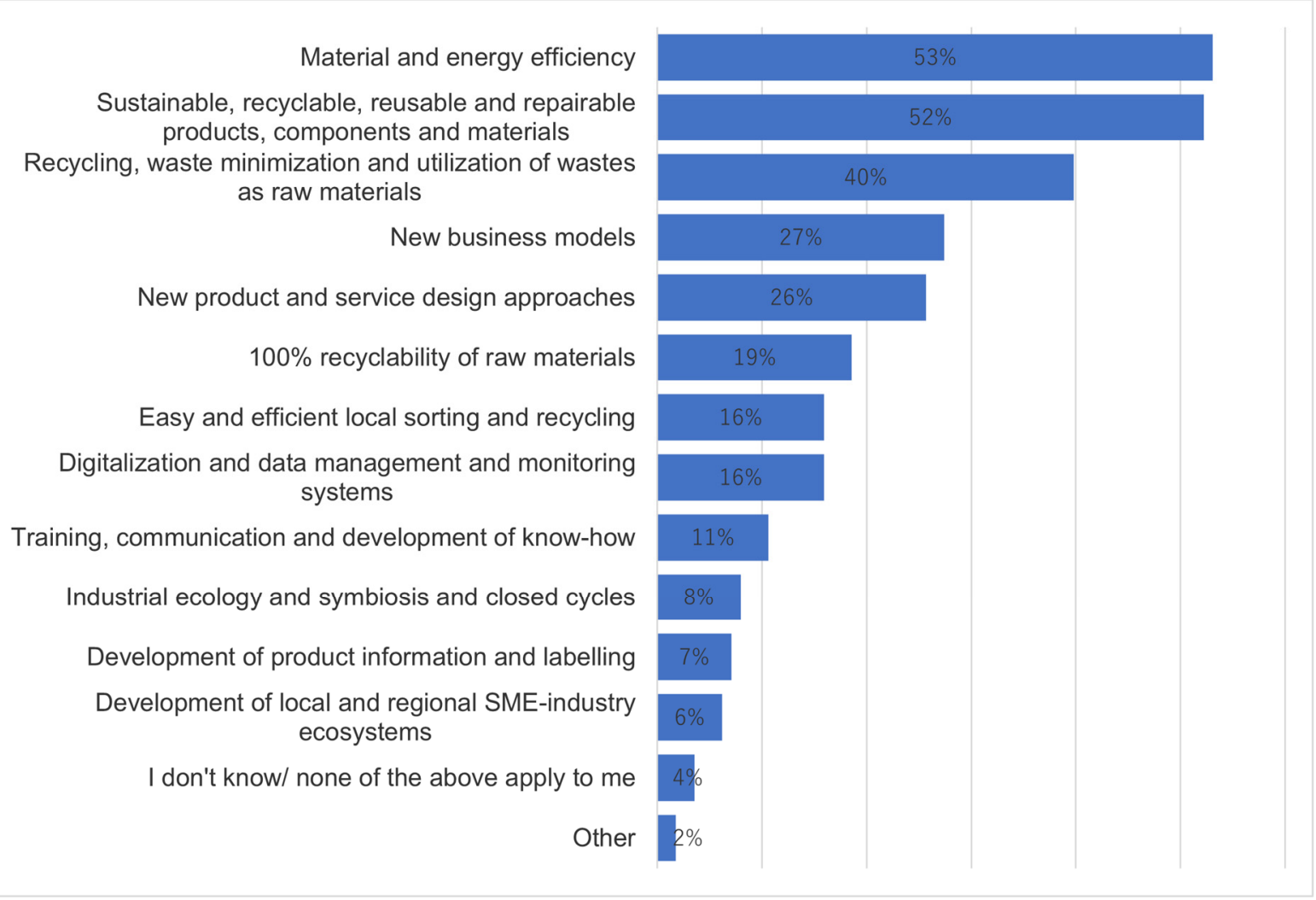

Figure 11. Best approaches to promote circular economy of material and energy use.

These findings suggest that it is important to focus on materials and energy with a special emphasis on, e.g., the existing, emerging, and potential sources of producing, and ways to produce, both renewable materials and energy accompanied by significant research, development, and innovation inputs. This issue is also related to the use of renewable raw materials to promote sustainable production, including addressing $\mathrm{CE}$ and sustainability requirements related to, e.g., the use of wood products, components, and materials. For example, the availability and price of recovered and reusable materials and components are major barriers to CE in the construction sector. Moreover, there is a need to streamline reuse and recycling, and to make these products easily accessible [64]. CE development within the building industry can be advanced through a higher degree of reused and optimized materials choice combinations (e.g., wood, steel, and glass) to promote a simplified disassembly for reuse and recycling [5].

It is noteworthy that the sustainable and cascading use of wood [39,40,52-57] is also essential in this context. The cascading use of wood can improve the overall performance of the wood utilization system and contribute to the reduction in associated environmental impacts [54]. For example, the establishment of a fully sustainable system requires focus on approaches, such as cascading of wood to ensure efficient use of resources and recovery of materials [52]. It is recommendable to prioritize material recovery (instead of energy recovery), including prolonging the life cycle of wood considering associated storage of biogenic carbon [40]. In addition, the achievement of high construction and demolition 
waste recycling rates requires major changes in the sorting, separation, and recovery of associated systems, with a focus on the critical aspects of wood recycling, such as solutions to waste wood that contains contaminants (e.g., nails, paints, or concrete) and wood recycling and material recovery (instead of energy use) considering environmental and economic performance aspects [55]. For example, the cascading use of wood requires the effective collection of waste wood, and it can reduce the global warming impact of wood utilization by $7 \%$, and the use of primary wood can be reduced up to $14 \%$ with a cascading of waste wood [54].

For example, modular construction has several benefits and advantages, but its application is still limited in the construction industry, and there is a need to assess its sustainability in a comprehensive manner based on suitable quantitative and qualitative sustainability performance criteria and indicators [32]. The implementation of $\mathrm{CE}$ within the construction industry and the application of CE to prefabricated buildings can be promoted based on strategies that focus on (1) higher levels of prefabrication through tender processes (higher weight); (2) project specification that cover the use of recycled materials; (3) new contracts for large valuable building items that cover maintenance and removal in addition to supply and installment; (4) adaptivity and future-proofing of buildings, (5) the deconstruct ability of, and recyclability of, components; and (6) buildings as material banks, and tracking of building components and their characteristics at the end of the life cycle of buildings based on the implementation of inter-organizational systems [65].

Circularity in the built environment can be advanced, e.g., through smart building dismantling and construction, as well as through demolition waste tools and protocols that drive investments towards closed loop construction [66]. It is noteworthy that $\mathrm{CE}$ principles and the recirculation of building materials (e.g., prolonged service life of building materials and components based on design for disassembly) can contribute to enhanced resource efficiency and help to retain value and durability of building materials [5]. In addition, CE action and circular transition in the construction sector requires focus on, e.g., (1) sustainable and durable materials; (2) design for disassembly; (3) modular and prefabricated elements; (4) recovery schemes and requirements for waste and demolition plans and standards to ensure quality of the recycled materials; (5) the sharing of information and technical performance; (6) the traceability of building materials; and (7) guidelines and training for demolition companies [10].

Practitioners can support the creation of circular supply chains and the reuse of building materials through (1) the establishment of material marketplaces for long-lived products, components, and resources (that can easily be exchanged between demolition sites and (re)development projects); and (2) the adoption of take-back schemes of suppliers for short-lived products [67]. Certain CE principles may be better suited for certain building types, materials, and components, which implies that focus is needed on the combination of specific life cycle design and construction strategies for different material and component groups and associated natural characteristics [5]. Additionally, businesses, public administration, and governments can manage their degree of $\mathrm{CE}$ implementation by using a $\mathrm{CE}$ measurement scale for the building industry, covering dimensions such as resource management, the efficient management of materials, energy and water, environmental impact, and indicators of CE transition [34]. For example, the 5R framework (rethink, reduce, reuse, repair, and recycle) can be used to understand and promote $C E$ concepts and practices in the construction industry [68].

\subsection{Barriers}

The results indicate that the technological, economical, and social barriers to the circular economy should be addressed first, including (1) the lack of general knowledge about circular economy opportunities and of seeing the "big picture"; (2) the little economic benefits associated with sorting and recycling (profitability); (3) sustainability marketing and consumer awareness; (4) the development of sustainable, recyclable, reusable, and 
repairable products, components, and materials; and (5) the creation of economic value and incentives (Figure 12).

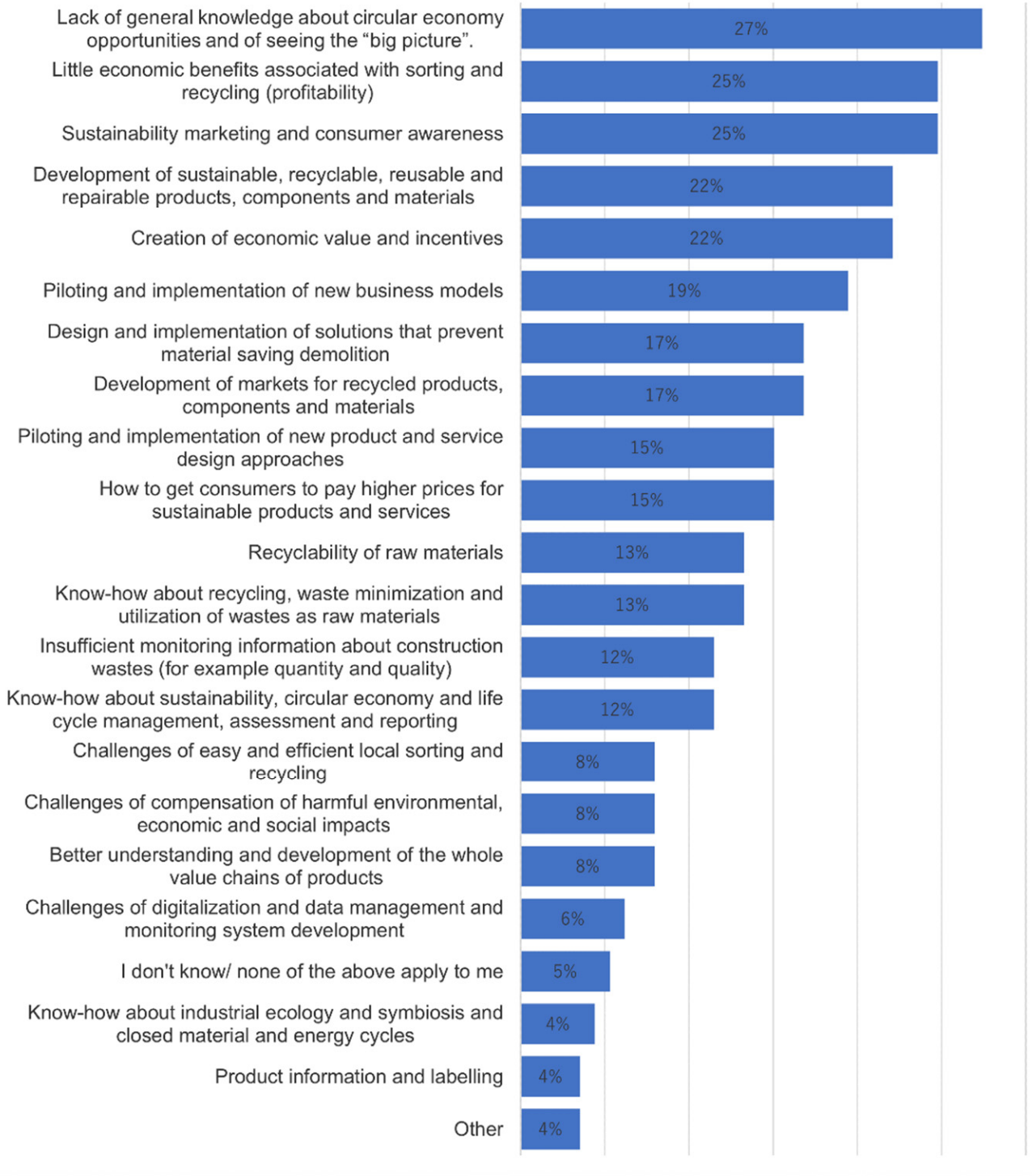

Figure 12. Technological, economical, and social barriers to circular economy that should be addressed first.

In addition, the answers for the other technological, economical, and social barriers to $C E$ that should be addressed first include (1) recycling combustible waste (that is used as fuel); (2) increased costs and wasted energy associated with easy sorting; (3) extending the life of buildings; (4) adding demolition potential to design; (5) insufficient monitoring information on construction waste (e.g., quantity and quality); (6) the barriers that wooden houses to renovation and demolition because of their integrated structure and use (demolition after use is, therefore, inevitable); and (7) the rejection of the introduction of a carbon tax.

These findings highlight the importance of promoting comprehensive CE knowledge (preferably covering the whole society), including consumer awareness, the integration of sustainability into marketing and overcoming barriers related to profitability, as well as economic value and incentives. Additionally, sustainable and CE-oriented products, components, and materials need strong focus in this context. This implies that the sustainable and cascading use of wood [39,40,52-57] is relevant for overcoming barriers to CE 
as well. These findings are also in accordance with the previously noted importance of environmental considerations of both society and markets as a driver for CE development in Japan [13]. In the case of $\mathrm{CE}$, the actors are typically firms and consumers; this orientation towards market solutions can lead to a reduction in the transaction costs of policy [16]. This means that raising awareness of $\mathrm{CE}$ will also reduce the burden on the policy-making side, such as the government and various ministries.

Previous studies have recognized various barriers to CE development in the construction and building sectors, such as (1) the lack of life cycle thinking and coordination, difficulties to adopt of new methods (e.g., use of new recycled materials and components), legislation obstacles, and contract models that do not support CE solutions [9]; (2) behavioral, technical, and legal barriers related to construction and demolition waste management (e.g., recyclability of construction materials, ineffective waste dismantling, sorting, transport, recovery processes, and ownership and agency issues in waste management) [69]; and (3) guaranteeing strength and safety (the reuse of structural timber), including the associated need for standardized assessment criteria to guarantee mechanical properties and to ensure the structural safety of buildings [40].

In addition, the identified barriers encompass (1) high complexity of the supply chain, focus on short-term goals (e.g., profit) that are not aligned with the long-term goals of sustainability and that result in insufficient stakeholder collaboration due to competition, and the lack of commonly agreed CE definitions that result in a lack of knowledge on how to practice impactful CE within the industry [5]; (2) upfront costs, project schedules/timelines, current business models, and lack of awareness and regulations [70]; (3) a lack of environmental laws and regulations, as well as support from public institutions and public awareness [7]; (4) lack of knowledge and tools [36]; and (5) lack of knowledge about the environmental performance and associated benefits of different building design and construction strategies (which implies that there is a need for new design typology to promote CE-oriented decision-making) [2].

Government policies influence the recovery of construction and demolition waste that is needed to achieve circularity and environmental sustainability in the construction sector [7]. Policies that could promote CE could encompass, e.g., production standards and norms, circular procurement, tax reliefs for circular products, the facilitation of waste trading through virtual platforms, and awareness building [71]. For example, digitalization has been recognized as a key driver of $C E$ and many barriers to $C E$, such as material availability, waste data, and quality of wastes, which can be solved through the implementation of online digital tools (e.g., tools for traceability) and supported by digital marketplaces for business-to-business trade of reusable products and recovered materials [64].

In addition, the transition to $C E$ in the construction sector requires government support, such as laws, tax incentives, and a systematic regulation and policy (including enhanced interaction among governmental institutions, policymakers, communities, and manufacturing industries) [62]. Circularity in the built environment can be advanced, e.g., through legislation on reuse and recycling thresholds for all new projects (which also promote fair competition and investments in innovative resource recovery), optimization of cost-effective processes, and governmental incentives and appreciation for stakeholders that are innovative and set benchmarks in circular construction [66]. Responses by society play a major role in the implementation of $\mathrm{CE}$ solutions, and there is a need to raise public awareness about the long-term benefits of CE solutions in the construction sector [45].

In addition, $\mathrm{CE}$ can be promoted, and many business opportunities can be created in the construction sector through implementation of local and national CE policies which focus on planning, requirements for public procurement, and requirements for sustainable construction [64]. The most relevant drivers for implementing CE in the construction sector include ecosystems, management commitment, the identification of valuable materials, and CE intermediaries [72]. As an example, a circular product supply chain can help to transform a linear building life cycle [36]. Targets are important governance instruments for a transition towards $\mathrm{CE}$ and to make the economy more circular. Furthermore, there 
is a need for new targets that reflect the multifaceted reality of $\mathrm{CE}$, including focus on, e.g., design improvements, a reduction in environmental impacts, the level of circularity, extended warranty, and repairability [73]. Public promotion of circular solutions should also include consideration of technological constraints and the provision of support for the development of product and service innovations [45].

\subsection{Guidance}

The results indicate that the particularly important areas in the development of CE guidance include (1) the design and manufacturing of sustainable, recyclable, reusable, and repairable products, components, and materials; (2) enhancement of consumer awareness; and (3) sustainable and renewable raw materials (Figure 13). Other important areas include life cycle management, assessment and reporting, new business models, enhancement of economic and social benefits, life cycle thinking, material and energy efficiency, and a reduction in the environmental impacts of production.

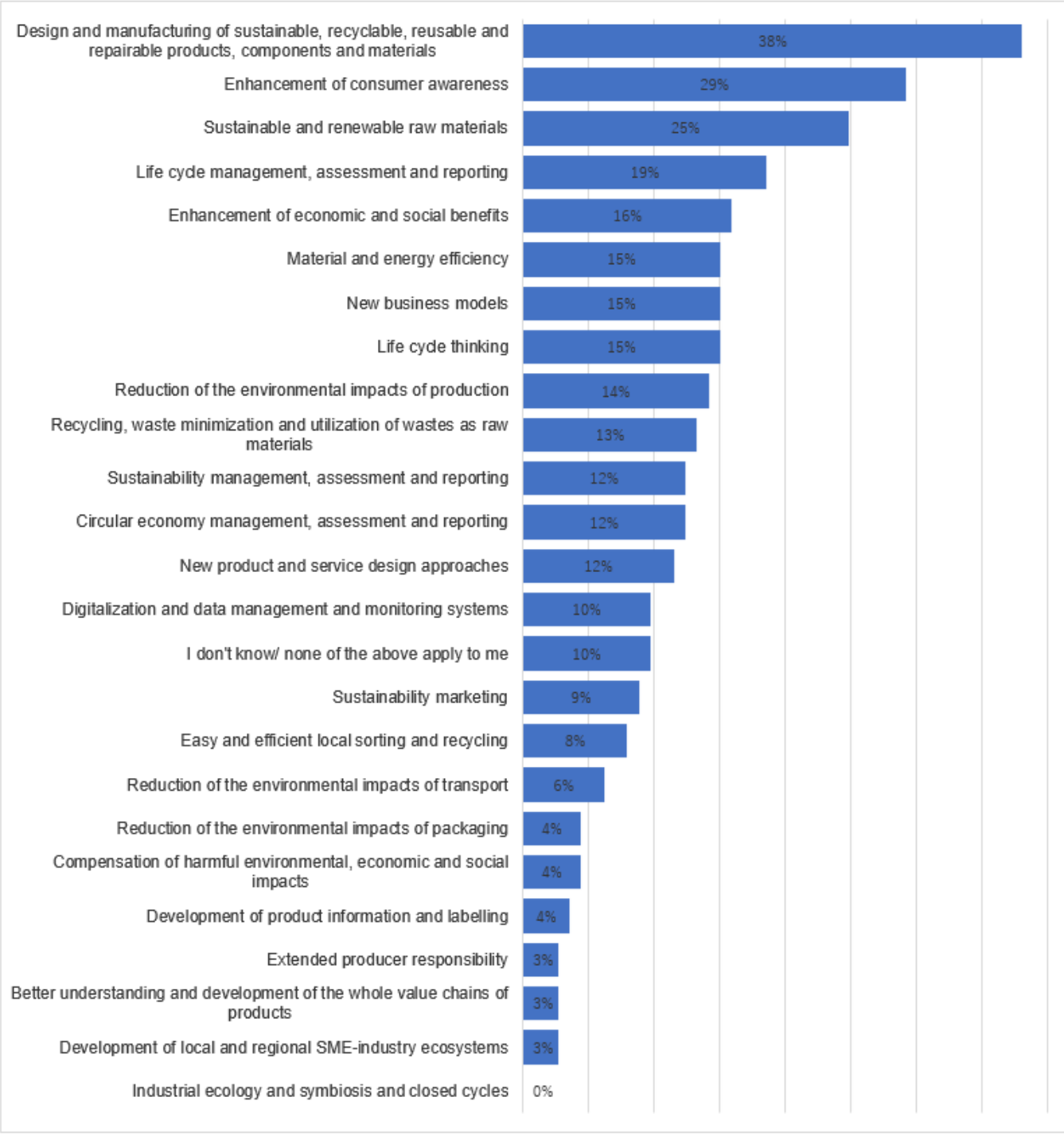

Figure 13. Particularly important areas in the development of circular economy guidance.

These finding suggest that the development of CE guidance should focus on the design and manufacturing of sustainable, recyclable, reusable and repairable products, components and materials. Sustainable and renewable raw materials are also among the priority focus areas. This implies that guidance is needed on sustainable and cascading use of wood [39,40,52-57] including focus on life cycle management, assessment and reporting. 
These findings are also in accordance with previous findings about the importance of the development of human resources for CE [21] and education for awareness raising and incentives [14] for CE development in Japan. Previous studies have recognized that education is among the main enabling factors that support transition to a CE model in the construction industry [70] and that education for CE is essential in the context of industrial design practices to advance design for circular production processes and circular consumption [51].

Many major construction companies are looking to integrate $\mathrm{CE}$ thinking into their business models and adopting CE practices, e.g., to enhance their material use, including minimization of natural resource inputs, and to optimize economic, social, environmental, and technical benefits and costs associated with full life cycles of products and materials [74]. In general, there is also a lack of clarity and insight related to circular business models in the construction sector [62], and sustainable business models also require new design capabilities [46]. However, some companies have implemented innovative and experimental initiatives, but comprehensive and widespread translation of $\mathrm{CE}$ thinking into construction practices is at an early stage [74]. All these sectoral efforts need to be supported by business support guidance and guidelines based on broader conception of the role of business in society [75].

In general, the transition to a CE model in the construction industry is supported by four main enabling factors: education, data availability, policies, and voluntary stewardships [70]. Higher education for CE should focus on, e.g., (1) specific circular business models (e.g., products as services and sharing platforms) and (2) the creation of innovation and entrepreneurship skills as well as encompass adoption of innovative and active learning approaches based on real problems and projects (e.g., collaboration with companies) [76] There is also a need for more focus on buildings in the CE-oriented building research, in addition to the current focus on construction materials, cities, or neighborhoods [3].

\subsection{Circular Economy Development}

The results indicate that the very important aspects of $\mathrm{CE}$ in the construction sector included (Figure 14): (1) the maintenance of existing buildings ( $72 \%$ of respondents); (2) sustainability and long-life cycles of products, components, and materials; (3) cooperation between the parties of the life cycle of construction; (4) products that are designed to be repaired and reused; and (5) sustainability criteria for the life cycle of construction (environmental, economical, and social aspects). These findings suggest that the maintenance of existing buildings is a major focus area that also could provide opportunities for novel innovations and application of $\mathrm{CE}$ and sustainability-oriented choices related to materials and energy. In addition, CE-oriented design; sustainability; and the extension of the use life and the overall life cycles of products, components, and materials are essential, including for the collaboration of all actors related to the whole life cycles of buildings. There is also a need for comprehensive sustainability management and assessment covering environmental, social, and economic aspects. In this context, there is a need to develop and apply a comprehensive set of sustainability criteria and indicators covering the whole life cycle of buildings.

These findings highlight the importance of the maintenance of existing buildings; a comprehensive approach to sustainability; long life cycles of products, components, and materials; and extensive cooperation covering all parties within the whole construction life cycle and of product design (including a focus on repair and reuse). This implies that the sustainable and cascading use of wood $[39,40,52-57]$ can play a major role in promoting CE in the construction sector and can contribute to all these priority aspects. In this context, it has been noted that that policy limitations related to wood cascading in the context of CE are seldom addressed in research [39] and that the increase in both the use and cascading of wood can contribute to a reduction in systemic environmental impacts [53]. Our previous research also suggests that (1) CE development can be promoted through public steering and enhanced focus on sustainability considerations [57]; (2) construction 
and buildings are among the main areas that offer the best opportunities to promote sustainable and CE-oriented public procurement in the future, including updating old buildings and spaces to combat climate change [77]; and (3) cascading of materials, such as solid wood, needs to be promoted through demand from the construction sector, other customers, or appropriate legal requirements or incentives [57]. These findings are also in accordance with previous findings about the need for closer links between all actors, levels, and units [15], and the importance of a people-centered approach (e.g., in the context of the lifespan extension of existing buildings) [17]. For example, cultural heritage buildings can promote environmental sustainability, and extending their useful lifespan can create multiple local benefits and contribute to social and economic development [36].

Guide for the planning and implementation of demolition and disassembly work

Circular economy criteria for all project phases

Easier product recycling and reuse within waste and chemical legislation

Sustainability criteria for the life cycle of construction (environmental, economical and social aspects)

Cooperation between the parties of the life cycle of construction

Development of information that promotes awareness of circular economy opportunities and of the "big picture"

Development of design and implementation solutions that promote material saving demolition

Development of monitoring information about construction wastes (for example quantity and quality)

Enhancement of economic benefits and profitability associated with sorting and recycling

Utilization of construction and demolition wastes as raw materials

Digital solutions for the recycling of buildings and materials (Buildings as Material Banks)

Components and materials that are designed to be disassembled and reused

Maintenance of existing buildings

Sustainability and long life cycles of products, components and materials

Products that are designed to be repaired and reused
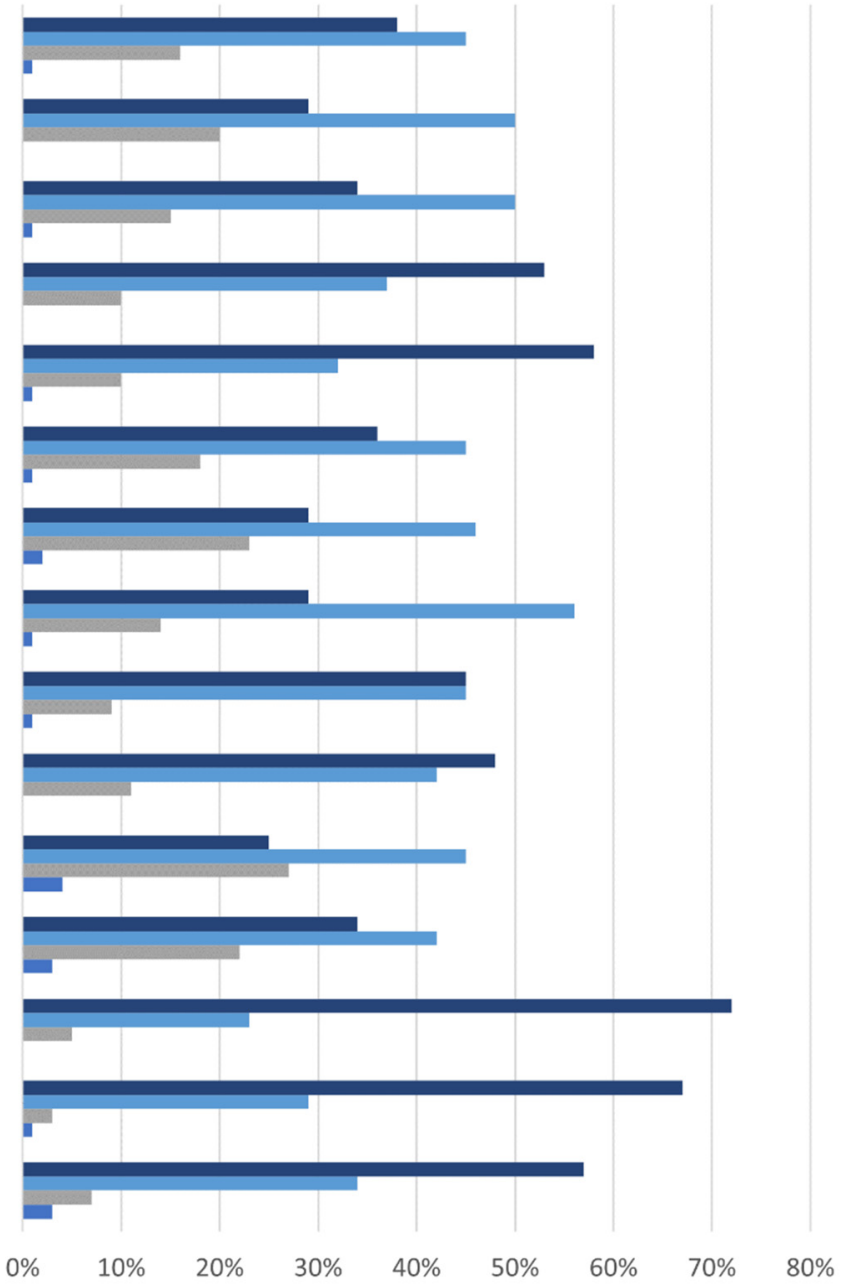

Eery important I Important $\quad$ Partly important Not at all important

Figure 14. The importance of specific $\mathrm{CE}$ aspects in the construction sector.

Previous studies have recognized that (1) refurbishment and the adaptive reuse of underutilized or abandoned buildings can create environmental and local benefits [36]; (2) $\mathrm{CE}$ in the construction and building sector requires adoption of new methods and comprehensive collaboration between stakeholders and among unconventional partners (e.g., to address cross-sectoral barriers to CE) [9]; (3) the introduction of the CE principle to the building industry can enhance its sustainability performance, and there is need for enhanced stakeholder participation in environmental impact assessments to promote practical applications and to support decision-making [42]; and (4) CE development in the 
construction industry requires a collaborative network of information brokers to bridge the structural holes (i.e., missing relations between parties) in the construction supply chain [8].

Additionally, there is a need to enhance the knowledge of standard practices within CE concepts and to develop standard practices for the reuse of building materials within the construction industry (e.g., CE practices in various life cycle stages, new CE-oriented business models, building material passports, and the creation of a community of practice) [78]. It has been noted that open-loop recycling, selective demolition, and prefabrication are popular circular strategies, whereas design for disassembly and in layers and closed-loop recycling have been less popular this sector [70]. CE development in the construction sector should ideally encompass the whole construction supply chain (many initial approaches have focused only on recycling and waste), and there are challenges, such as the risk of using the CE concept to justify unsustainable economic growth [74]. The effective implementation of $\mathrm{CE}$ in the whole construction value chain requires clarity on how circular actions contribute to sustainability, business models, supply chains, and innovation and communication technology systems [62]. CE development in the building sector also requires new types of collaboration within supply chains [10].

Finally, the promotion of CE in the built environment requires, e.g., inclusive and adaptive management, multidisciplinary approaches, practices to extend service lives, product-service systems, and the establishment of a database or platform for a continuously updated, evaluated, and interconnected set of best practices [4]. The development of circular buildings requires (1) a new process design based on the early integration of multiple disciplines in the supply chain; (2) an ambitious vision based on co-creation; (3) the extension of responsibilities to all actors in the whole building supply chain; and (4) new business and ownership models [67]. The realization of the benefits of CE implementation in the construction industry also requires specific case studies, including real implications [10].

\section{Conclusions}

The findings of this study suggest that CE development priority focus areas in the construction sector in Japan encompass (in relation to the study themes): (1) the use of renewable raw materials, including sustainable production; (2) the enhancement of consumer awareness (sustainable consumption); (3) sustainable, recyclable, reusable, and repairable products, components, and materials, as well as sustainable and renewable raw materials (CE innovations); (4) sustainable, recyclable, reusable, and repairable products, components, and materials, as well as material and energy efficiency (CE of material and energy use); (5) a lack of general knowledge surrounding circular economy opportunities and of seeing the "big picture", the little economic benefits associated with sorting and recycling (profitability), sustainability marketing, and consumer awareness, as well as the development of sustainable, recyclable, reusable, and repairable products, components, and materials for the creation of economic value and incentives (technological, economical, and social barriers to CE); (6) design and manufacturing of sustainable, recyclable, reusable, and repairable products, components, and materials, as well as enhancement of consumer awareness and sustainable and renewable raw materials (CE guidance); and (7) the maintenance of existing buildings (72\% of respondents), as well as the sustainability and long life cycles of products, components, and materials, or the cooperation between the parties of the life cycle of construction and products that are designed to be repaired and reused with sustainability criteria for the life cycle of construction, including environmental, economical, and social aspects (specific CE aspects in the construction sector).

These findings and identified priority focus areas can potentially contribute to further the development of $\mathrm{CE}$ in the construction sector through their appropriate integration into proactive management, informed decision-making, and to sustainability and CEoriented design and engineering among all relevant construction sector organizations. Future research should focus on more in-depth assessment of the main findings associated with each study theme, including strong emphasis on the contribution to management, informed decision-making and sustainability, and CE-oriented design and engineering in 
the construction sector. Real-life case studies and transdisciplinary approaches are highly recommended. More focus is needed on the identified priority areas, including ways to overcome the main barriers and to create and develop an appropriate enabling environment for $\mathrm{CE}$ in the construction sector.

Author Contributions: Conceptualization, R.H. and D.S.; methodology, R.H. and D.S.; software, D.S.; validation, D.S. and R.H.; formal analysis, R.H. and D.S.; investigation, R.H. and D.S.; resources, R.H. and D.S.; data curation, D.S. and R.H.; writing-original draft preparation, R.H. and D.S.; writing - review and editing, R.H. and D.S.; visualization, R.H. and D.S.; supervision, R.H. and D.S.; project administration, R.H. and D.S.; funding acquisition, R.H. and D.S. All authors have read and agreed to the published version of the manuscript.

Funding: This research received no external funding.

Institutional Review Board Statement: The study was conducted according to the guidelines of the Declaration of Helsinki and ethical review process guidance at both Nihon Fukushi University and Aalto University was followed.

Informed Consent Statement: Not applicable.

Data Availability Statement: Research data are available from the authors upon request.

Conflicts of Interest: The authors declare no conflict of interest.

\section{References}

1. Ellen McArthur Foundation. Towards a Circular Economy: Business Rationale for an Accelerated Transition. Available online: https:/ / emf.thirdlight.com/link/ip2fh05h21it-6nvypm (accessed on 19 October 2021).

2. Eberhardt, L.C.M.; Birkved, M.; Birgisdottir, H. Building design and construction strategies for a circular economy. Archit. Eng. Des. Manag. 2020, 225, 12055. [CrossRef]

3. Pomponi, F.; Moncaster, A. Circular economy for the built environment: A research framework. J. Clean. Prod. 2017, 143, 710-718. [CrossRef]

4. Joensuu, T.; Edelman, H.; Saari, A. Circular economy practices in the built environment. J. Clean. Prod. 2020, 276, 124215. [CrossRef]

5. Eberhardt, L.C.M.; Birgisdottir, H.; Birkved, M. Potential of Circular Economy in Sustainable Buildings. IOP Conf. Ser. Mater. Sci. Eng. 2019, 471, 92051. [CrossRef]

6. Andrews, D. The Circular Economy, Design Thinking and Education for Sustainability. Local Econ. 2015, 30, 305-315. [CrossRef]

7. Díaz-López, C.; Bonoli, A.; Martín-Morales, M.; Zamorano, M. Analysis of the Scientific Evolution of the Circular Economy Applied to Construction and Demolition Waste. Sustainability 2021, 13, 9416. [CrossRef]

8. Wijewickrama, M.K.C.S.; Rameezdeen, R.; Chileshe, N. Information brokerage for circular economy in the construction industry: A systematic literature review. J. Clean. Prod. 2021, 313, 127938. [CrossRef]

9. Karhu, J.; Linkola, L. Circular economy in the built environment in finland-A case example of collaboration. IOP Conf. Ser. Earth Environ. Sci. 2019, 297, 12024. [CrossRef]

10. Hossain, M.U.; Ng, S.T.; Antwi-Afari, P.; Amor, B. Circular economy and the construction industry: Existing trends, challenges and prospective framework for sustainable construction. Renew. Sustain. Energy Rev. 2020, 130, 109948. [CrossRef]

11. Sitra. Summary of Closing Remarks from the WCEF 2018 Hosts. Available online: https:/ /www.sitra.fi/en/articles/summaryof-closing-remarks-from-wcef-2018-hosts / (accessed on 2 December 2021).

12. Sitra. WCEF2018 Report. Available online: https://media.sitra.fi/2018/11/20141120/sitramoejwcef2018report.pdf (accessed on 7 December 2021).

13. Ministry of Economy, Trade and Industry of Japan. Circular Economy Vision 2020. Available online: https://www.meti.go.jp/ english/press /2020/0522_003.html\#: \{\}:text=Aiming\%20to\%20present $\% 20$ basic $\% 20$ future, abroad $\% 20$ and $\% 20$ analyzed $\% 20$ the\%20results (accessed on 6 December 2021).

14. Ogunmakinde, O.E. A Review of Circular Economy Development Models in China, Germany and Japan. Recycling 2019, 4, 27. [CrossRef]

15. Umeda, Y.; Takata, S.; Matsumoto, M. Technical Committee for Life Cycle Engineering: Life Cycle Engineering in the Era of Circular Economy. J. Jpn. Soc. Precis. Eng. 2019, 85, 817-820. [CrossRef]

16. Teramoto, H. An Inquiry into the Influence Plastic giving to the Economic Society-Transition from Linear Economy to Circular Economy. Aichi Gakuin Econ. Rev. 2020, 8, 83-97.

17. Wuyts, W.; Miatto, A.; Sedlitzky, R.; Tanikawa, H. Extending or ending the life of residential buildings in Japan: A social circular economy approach to the problem of short-lived constructions. J. Clean. Prod. 2019, 231, 660-670. [CrossRef]

18. Japan's Circularity. A Panorama of Japansese Policy, Innovation, Technology and Industry Contributions towards Achieving the Paris Agreement. EU-Japan Centre for Industrial Cooperation. Available online: https: / www.eu-japan.eu/sites/default/files / publications/docs/japans_circularity_-_helene_bangert_-_11.12.2020.pdf (accessed on 6 December 2021). 
19. Hosoda, E. Recent Developments in Circular Economies: A Comparative Study of the EU and Japan. Mater. Cycles Waste Manag. Res. 2015, 26, 253-260. [CrossRef]

20. Benton, D.; Hazell, J. The Circular Economy in Japan. 2015. Available online: https://www.the-ies.org/analysis/circulareconomy-japan (accessed on 2 December 2021).

21. Kasuga, H. The Dawn of Reiwa Modernism: "Circular Economy" Adopted Emotional Feelings. Int. J. Affect. Eng. 2021, 19, 23-28. [CrossRef]

22. Saldana, J. Fundamentals of Qualitative Research; Oxford University Press: Oxford, UK, 2011; pp. 3-30, ISBN -10:0199737959.

23. Patten, M.L. Questionnaire Research: A Practical Guide, 4th ed.; Routledge: New York, NY, USA, 2014. [CrossRef]

24. Gillham, B. Developing a Questionnaire, 2nd ed.; Continuum International Publishing Group: London, UK, 2007 ; ISBN 10:0826496318.

25. Hirsjärvi, H.; Remes, P.; Sajavaara, P. Tutki ja Kirjoita, 13th ed.; Tammi: Helsinki, Finland, 2007; ISBN 978-951-26-5635-6.

26. Birmingham, P.; Wilkinson, D. Using Research Instruments: A Guide for Researchers; Taylor \& Francis Group: Abingdon-on-Thames, UK, 2003; ISBN 9780415272797.

27. Fink, A. How to Conduct Surveys: A Step-By-Step Guide, 4th ed.; Sage: Newcastle upon Tyne, UK, 2009; ISBN 10:141296668X.

28. Oppenheim, A.N. Questionnaire Design, Interviewing and Attitude Measurement; Pinter: London, UK; Washington, DC, USA, 1997; ISBN 10:0826451764.

29. Saris, W.E.; Gallhofer, I.N. Design, Evaluation, and Analysis of Questionnaires for Survey Research; John Wiley \& Sons: Hoboken, NJ, USA, 2007; ISBN 10:0470114959.

30. Sudman, S.; Bradbrun, N.M. Asking Questions: A Practical Guide to Questionnaire Design; The Jossey-Bass Series in Social and Behavioural Sciences; Jossey-Bass Publishers: Hoboken, NJ, USA, 1982; ISBN 9780985895464.

31. Peterson, R.A. Constructing Effective Questionnaires; SAGE Publications: Thousand Oaks, CA, USA, 2000. [CrossRef]

32. Kamali, M.; Hewage, K. Life cycle performance of modular buildings: A critical review. Renew. Sustain. Energy Rev. 2016, 62, 1171-1183. [CrossRef]

33. Braganca, L.; Mateus, R.; Koukkari, H. Perspectives of building sustainability assessment. In Portugal SB07. Sustainable Construction, Materials and Practices: Challenge of the Industry for the New Millennium; Braganca, L., Pinheiro, M.D., Jalali, S., Mateus, R., Amoeda, R., Guedes, M.C., Eds.; IOS Press: Amsterdam, The Netherlands, 2007; pp. 356-365. ISBN 9781586037857.

34. Nuñez-Cacho, P.; Górecki, J.; Molina-Moreno, V.; Corpas-Iglesias, F.A. What Gets Measured, Gets Done: Development of a Circular Economy Measurement Scale for Building Industry. Sustainability 2018, 10, 2340. [CrossRef]

35. Akadiri, P.O.; Chinyio, E.A.; Olomolaiye, P.O. Design of A Sustainable Building: A Conceptual Framework for Implementing Sustainability in the Building Sector. Buildings 2012, 2, 126-152. [CrossRef]

36. Foster, G. Circular economy strategies for adaptive reuse of cultural heritage buildings to reduce environmental impacts. Resour. Conserv. Recycl. 2020, 152, 104507. [CrossRef]

37. Saidani, M.; Yannou, B.; Leroy, Y.; Cluzel, F. How to Assess Product Performance in the Circular Economy? Proposed Requirements for the Design of a Circularity Measurement Framework. Recycling 2017, 2, 6. [CrossRef]

38. Papastamoulis, V.; London, K.; Feng, Y.; Zhang, P.; Crocker, R.; Patias, P. Conceptualising the Circular Economy Potential of Construction and Demolition Waste: An Integrative Literature Review. Recycling 2021, 6, 61. [CrossRef]

39. Jarre, M.; Petit-Boix, A.; Priefer, C.; Meyer, R.; Leipold, S. Transforming the bio-based sector towards a circular economy-What can we learn from wood cascading? For. Policy Econ. 2020, 110, 101872. [CrossRef]

40. Niu, Y.; Rasi, K.; Hughes, M.; Halme, M.; Fink, G. Prolonging life cycles of construction materials and combating climate change by cascading: The case of reusing timber in Finland. Resour. Conserv. Recycl. 2021, 170, 105555. [CrossRef]

41. Murray, A.; Skene, K.; Haynes, K. The circular economy: An interdisciplinary exploration of the concept and application in a global context. J. Bus. Ethics 2017, 140, 369-380. [CrossRef]

42. Hossain, M.U.; Ng, S.T. Critical consideration of buildings' environmental impact assessment towards adoption of circular economy: An analytical review. J. Clean. Prod. 2018, 205, 763-780. [CrossRef]

43. Ginga, C.P.; Ongpeng, J.M.C.; Daly, M.K.M. Circular Economy on Construction and Demolition Waste: A Literature Review on Material Recovery and Production. Materials 2020, 13, 2970. [CrossRef]

44. Xue, K.; Hossain, M.U.; Liu, M.; Ma, M.; Zhang, Y.; Hu, M.; Chen, X.; Cao, G. BIM Integrated LCA for Promoting Circular Economy towards Sustainable Construction: An Analytical Review. Sustainability 2021, 13, 1310. [CrossRef]

45. Tomaszewska, J. Polish Transition towards Circular Economy: Materials Management and Implications for the Construction Sector. Materials 2020, 13, 5228. [CrossRef]

46. De los Rios, I.C.; Charnley, F.J.S. Skills and capabilities for a sustainable and circular economy: The changing role of design. J. Clean. Prod. 2017, 160, 109-122. [CrossRef]

47. Ghisellini, P.; Ripa, M.; Ulgiati, S. Exploring environmental and economic costs and benefits of a circular economy approach to the construction and demolition sector. A literature review. J. Clean. Prod. 2018, 178, 618-643. [CrossRef]

48. Rahla, K.M.; Mateus, R.; Bragança, L. Selection Criteria for Building Materials and Components in Line with the Circular Economy Principles in the Built Environment-A Review of Current Trends. Infrastructures 2021, 6, 49. [CrossRef]

49. Mercader-Moyano, P.; Porras-Pereira, P.; Levinton, C. Circular Economy and Regenerative Sustainability in Emergency Housing: Eco-Efficient Prototype Design for Subaşi Refugee Camp in Turkey. Sustainability 2021, 13, 8100. [CrossRef]

50. Jensen, J.O.; Jørgensen, M.S.; Lauridsen, M.E.; Lauridsen, E.H. Has social sustainability left the building? The recent conceptualization of "sustainability" in Danish buildings. Sustain. Sci. Pract. Policy 2012, 8, 94-105. [CrossRef] 
51. van Dam, K.; Simeone, L.; Keskin, D.; Baldassarre, B.; Niero, M.; Morelli, N. Circular Economy in Industrial Design Research: A Review. Sustainability 2020, 12, 10279. [CrossRef]

52. Sakaguchi, D.; Takano, A.; Hughes, M. The potential for cascading wood from demolished buildings: Potential flows and possible applications through a case study in Finland. Int. Wood Prod. J. 2017, 8, 208-215. [CrossRef]

53. Mehr, J.; Vadenbo, C.; Steubing, B.; Hellweg, S. Environmentally optimal wood use in Switzerland-Investigating the relevance of material cascades. Resour. Conserv. Recycl. 2018, 131, 181-191. [CrossRef]

54. Höglmeier, K.; Steubing, B.; Weber-Blaschke, G.; Richter, K. LCA-based optimization of wood utilization under special consideration of a cascading use of wood. J. Environ. Manag. 2015, 152, 158-170. [CrossRef]

55. Dahlbo, H.; Bacher, J.; Lahtinen, K.; Jouttijärvi, T.; Suoheimo, P.; Mattila, T.; Sironen, S.; Myllymaa, T.; Saramaki, K. Construction and demolition waste management e a holistic evaluation of environmental performance. J. Clean. Prod. 2015, 107, 333-341. [CrossRef]

56. Sakaguchi, D.; Takano, A.; Hughes, M. The potential for cascading wood from demolished buildings: The condition of recovered wood through a case study in Finland. Int. Wood Prod. J. 2016, 7, 137-143. [CrossRef]

57. Husgafvel, R.; Linkosalmi, L.; Hughes, M.; Kanerva, J.; Dahl, O. Forest sector circular economy in Finland: A regional study on sustainability driven competitive advantage and an assessment of the potential for cascading recovered solid wood. J. Clean. Prod. 2018, 181, 483-497. [CrossRef]

58. Ruiz, L.A.L.; Ramón, X.R.; Domingo, S.G. The circular economy in the construction and demolition waste sector-A review and an integrative model approach. J. Clean. Prod. 2020, 248, 119238. [CrossRef]

59. Bertino, G.; Kisser, J.; Zeilinger, J.; Langergraber, G.; Fischer, T.; Österreicher, D. Fundamentals of Building Deconstruction as a Circular Economy Strategy for the Reuse of Construction Materials. Appl. Sci. 2021, 11, 939. [CrossRef]

60. Sumter, D.; de Koning, J.; Bakker, C.; Balkenende, R. Key Competencies for Design in a Circular Economy: Exploring Gaps in Design Knowledge and Skills for a Circular Economy. Sustainability 2021, 13, 776. [CrossRef]

61. Sumter, D.; de Koning, J.; Bakker, C.; Balkenende, R. Circular Economy Competencies for Design. Sustainability 2020, 12, 1561. [CrossRef]

62. Munaro, M.R.; Tavares, S.F.; Bragança, L. Towards circular and more sustainable buildings: A systematic literature review on the circular economy in the built environment. J. Clean. Prod. 2020, 260, 121134. [CrossRef]

63. Ellen McArthur Foundation. Circular Design. Available online: https://archive.ellenmacarthurfoundation.org/explore/circulardesign (accessed on 15 October 2021).

64. zu Castell-Rüdenhausen, M.; Wahlström, M.; Astrup, T.F.; Jensen, C.; Oberender, A.; Johansson, P.; Waerner, E.R. Policies as Drivers for Circular Economy in the Construction Sector in the Nordics. Sustainability 2021, 13, 9350. [CrossRef]

65. Minunno, R.; O'Grady, T.; Morrison, G.M.; Gruner, R.L.; Colling, M. Strategies for Applying the Circular Economy to Prefabricated Buildings. Buildings 2018, 8, 125. [CrossRef]

66. Ghaffar, S.H.; Burman, M.; Braimah, N. Pathways to circular construction: An integrated management of construction and demolition waste for resource recovery. J. Clean. Prod. 2020, 244, 118710. [CrossRef]

67. Leising, E.; Quist, J.; Bocken, N. Circular Economy in the building sector: Three cases and a collaboration tool. J. Clean. Prod. 2018, 176, 976-989. [CrossRef]

68. Tserng, H.-P.; Chou, C.-M.; Chang, Y.-T. The Key Strategies to Implement Circular Economy in Building Projects-A Case Study of Taiwan. Sustainability 2021, 13, 754. [CrossRef]

69. Mahpour, A. Prioritizing barriers to adopt circular economy in construction and demolition waste management. Resour. Conserv. Recycl. 2018, 134, 216-227. [CrossRef]

70. Guerra, B.C.; Leite, F. Circular economy in the construction industry: An overview of United States stakeholders' awareness, major challenges, and enablers. Resour. Conserv. Recycl. 2021, 170, 105617. [CrossRef]

71. Hartley, K.; van Santen, R.; Kirchherr, J. Policies for transitioning towards a circular econ-omy: Expectations from the European Union (EU). Resour. Conserv. Recycl. 2020, 155, 104634. [CrossRef]

72. Torres-Guevara, L.E.; Prieto-Sandoval, V.; Mejia-Villa, A. Success Drivers for Implementing Circular Economy: A Case Study from the Building Sector in Colombia. Sustainability 2021, 13, 1350. [CrossRef]

73. Morseletto, P. Targets for a circular economy. Resour. Conserv. Recycl. 2020, 153, 104553. [CrossRef]

74. Jones, P.; Comfort, D. The construction industry and the circular economy. Int. J. Manag. Cases 2018, 20, 4-15. Available online: http:/ / eprints.glos.ac.uk/id/eprint/5562 (accessed on 22 October 2021).

75. Velenturf, A.P.M.; Jensen, P.D.; Purnell, P.; Jopson, J.; Ebner, N. A Call to Integrate Economic, Social and Environmental Motives into Guidance for Business Support for the Transition to a Circular Economy. Adm. Sci. 2019, 9, 92. [CrossRef]

76. Giannoccaro, I.; Ceccarelli, G.; Fraccascia, L. Features of the Higher Education for the Circular Economy: The Case of Italy. Sustainability 2021, 13, 11338. [CrossRef]

77. Husgafvel, R.; Linkosalmi, L.; Sakaguchi, D.; Hughes, M. How to advance sustainable and circular economy oriented public procurement?-A review of the operational environment and a case study from the Kymenlaakso region in Finland. In Circular Economy and Sustainability, Volume 1: Management and Policy; Elsevier: Amsterdam, The Netherlands, 2022; pp. 227-277. [CrossRef]

78. Benachio, G.L.F.; Freitas, M.C.D.; Tavares, S.F. Circular economy in the construction industry: A systematic literature review. J. Clean. Prod. 2020, 260, 121046. [CrossRef] 